\title{
The top 100 cited cholesterol papers
}

\author{
Aaron A. Sorensen ${ }^{\mathrm{a}, *}$ and David Weedon ${ }^{\mathrm{b}}$ \\ ${ }^{a}$ ÜberResearch - Digital Science, Inc., Cambridge, MA, USA \\ ${ }^{\mathrm{b}}$ IOS Press, Amsterdam, The Netherlands
}

\begin{abstract}
We have compiled a list of the 100 most cited articles in cholesterol research to assess research trends over the last 10 and 100 years to mark the 200th anniversary of the naming of cholesterol as part of the special issue of Biomedical Spectroscopy and Imaging.
\end{abstract}

Keywords: Cholesterol

\section{Introduction}

2016 is the 200th anniversary of the naming of cholesterol [1] and as part of the special issue of Biomedical Spectroscopy and Imaging to mark this milestone, this article presents an analysis of the most cited articles on cholesterol in an attempt to identify the most widely read and influential articles on the subject and give the authors the recognition they deserve. Such an analysis of cited papers can also identify trends, provide guidance for future research and highlight where there are insufficiencies in the current literature $[1,2]$.

\section{Methods and limitations}

As with many areas of biomedicine, the field of cholesterol research historically has had a strong divide between biochemical and physiological investigations. As we began the process of selecting the 100-most-cited papers in the field this divide was in clear evidence. Most of the papers fell into one of the following categories:

(1) Methods for measuring cholesterol

(2) Cholesterol metabolism/homeostasis

(3) Cholesterol and disease

(4) Cholesterol lowering drugs

(5) Cholesterol biochemistry/biophysics

While the major interest of the journal is in the fifth category we felt it would also be interesting to look at the wider picture to mark this anniversary. Citation data are not readily available for papers published more than 100 years ago and for this reason we focused on the last 100 years and also, for comparison the last 10 years.

\footnotetext{
${ }^{*}$ Corresponding author. E-mail: aaron@uberresearch.com.
} 
It is important to recognize that any search strategy represents an approximation to the field.

The data used in the tabulation of each originate from the Web of Science Core Collection database which includes but is not limited to all papers indexed by the NIH's Medline database. Two selection filters were used to determine which papers would contribute to an article's metrics. The first requirement was that all papers to be included in the analysis contained the search term "cholesterol" in the title field. Reviews were included in the analysis because, while it is relatively "easy" to write a review, it is very difficult to write a review that is well cited. Well-cited reviews tend to be authored by leaders in the field and present conceptual advances or new hypotheses that can be as important as experimental advances.

The second filter is temporal: only papers published and subsequently indexed in Web of Science Core Collection between January 1, 1916 and December 31, 2015 were considered for the 100 year analysis and only papers published and subsequently indexed in Web of Science Core Collection between January 1, 2006 and December 31, 2015 were considered for the 10 year analysis. The queries for the two document sets were conducted on February 2, 2016 and March 29, 2016 respectively.

It is important to recognize that citation scores are, by necessity, close approximations rather than absolute values, the latter not being possible because all citation tools have slightly different variables (e.g. journals indexed, time period covered, data reliability).

\section{Results}

Table 1

Most-cited papers in cholesterol between January 1, 1916 and December 31, 2015

\begin{tabular}{|c|c|c|c|c|c|}
\hline Rank & Year & Authors & Title & Journal & $\begin{array}{l}\text { Times } \\
\text { cited }\end{array}$ \\
\hline 1 & 1972 & Friedewa, WT; Fredrick, DS; Levy, RI & $\begin{array}{l}\text { Estimation of concentration } \\
\text { of low-density lipoprotein } \\
\text { cholesterol in plasma, } \\
\text { without use of preparative } \\
\text { ultracentrifuge }\end{array}$ & $\begin{array}{l}\text { CLINICAL } \\
\text { CHEMISTRY }\end{array}$ & 16,697 \\
\hline 2 & 2001 & $\begin{array}{l}\text { Cleeman, JI; Grundy, SM; Becker, D; } \\
\text { Clark, LT; Cooper, RS; Denke, MA; } \\
\text { Howard, WJ; Hunninghake, DB; } \\
\text { Illingworth, DR; Luepker, RV; McBride, } \\
\text { P; McKenney, JM; Pasternak, RC; Stone, } \\
\text { NJ; Van Horn, L; Brewer, HB; Ernst, } \\
\text { ND; Gordon, D; Levy, D; Rifkind, B; } \\
\text { Rossouw, JE; Savage, P; Haffner, SM; } \\
\text { Orloff, DG; Proschan, MA; Schwartz, JS; } \\
\text { Sempos, CT; Shero, ST; Murray, EZ }\end{array}$ & $\begin{array}{l}\text { Executive summary of the } \\
\text { Third Report of the } \\
\text { National Cholesterol } \\
\text { Education Program } \\
\text { (NCEP) expert panel on } \\
\text { detection, evaluation, and } \\
\text { treatment of high blood } \\
\text { cholesterol in adults (Adult } \\
\text { Treatment Panel III) }\end{array}$ & $\begin{array}{l}\text { JAMA-JOURNAL } \\
\text { OF THE } \\
\text { AMERICAN } \\
\text { MEDICAL } \\
\text { ASSOCIATION }\end{array}$ & 12,564 \\
\hline 3 & 1994 & $\begin{array}{l}\text { Pedersen, TR; Kjekshus, J; Berg, K; } \\
\text { Haghfelt, T; Faergeman, O; } \\
\text { Thorgeirsson, G; Pyorala, K; Miettinen, } \\
\text { T; Wilhelmsen, L; Olsson, AG; Wedel, } \\
\text { H; Kristianson, K; Thomsen, H; Nordero, } \\
\text { E; Thomsen, B; Lyngborg, K; Andersen, } \\
\text { GS; Nielsen, F; Talleruphuus, U; Mcnair, } \\
\text { A; Egstrup, K; Simonsen, EH; Simonsen, } \\
\text { I; Vejbychristensen, H; Sommer, L; } \\
\text { Eidner, PO; Klarholt, E; Henriksen, A; }\end{array}$ & $\begin{array}{l}\text { Randomized trial of } \\
\text { cholesterol-lowering in } \\
4444 \text { patients with } \\
\text { coronary-heart-disease - } \\
\text { The Scandinavian } \\
\text { Simvastatin Survival Study } \\
\text { (4S) }\end{array}$ & LANCET & 7573 \\
\hline
\end{tabular}


Table 1

(Continued)

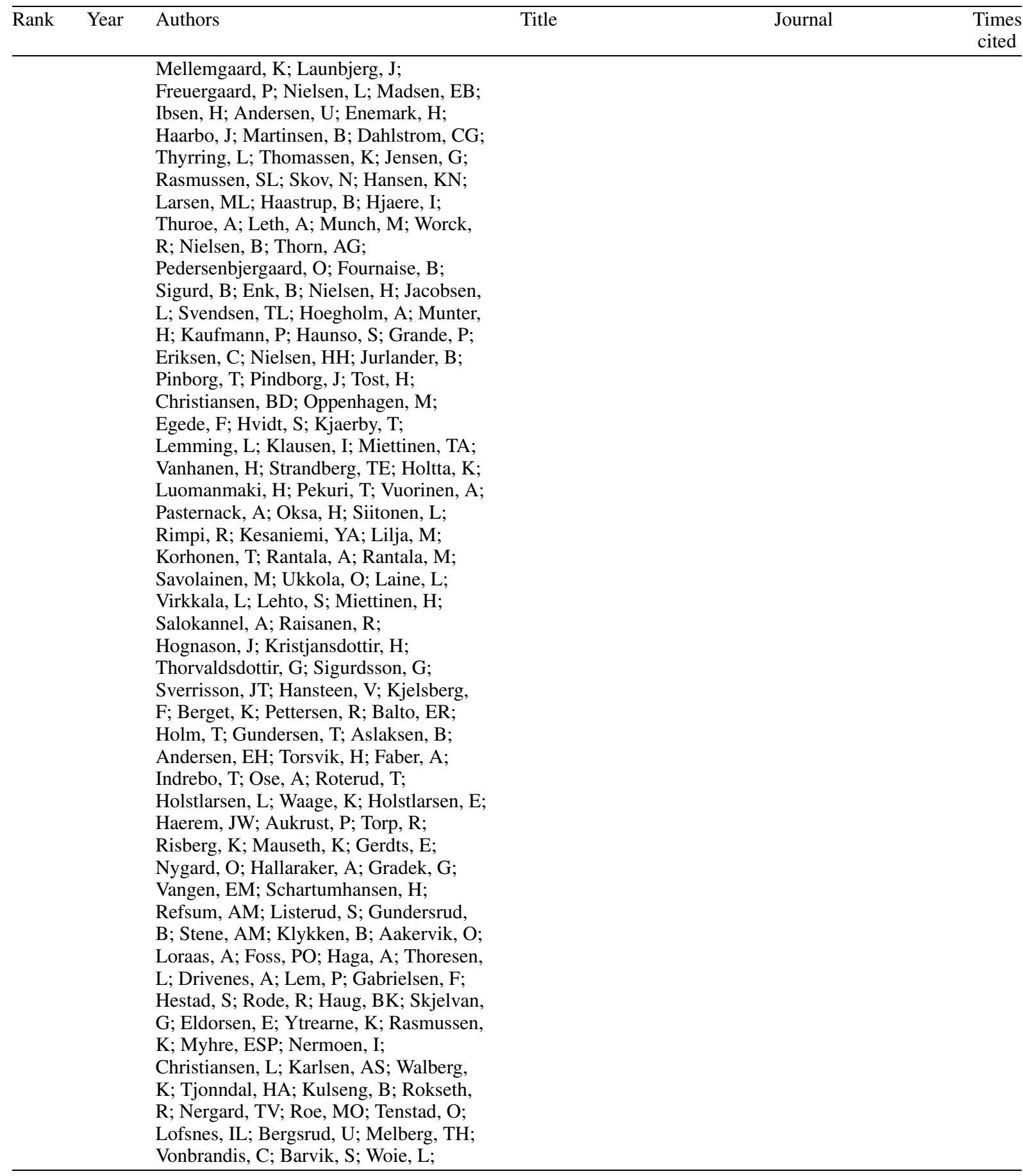


Table 1

(Continued)

\begin{tabular}{|c|c|c|c|}
\hline Rank & Authors & Journal & $\begin{array}{l}\text { Times } \\
\text { cited }\end{array}$ \\
\hline & $\begin{array}{l}\text { Abrahamsen, AM; Aarsland, T; Svanes, } \\
\text { H; Noer, G; Nordlie, KE; Hanedalen, } \\
\text { AE; Johansen, T; Larsen, CB; Ostholm, } \\
\text { E; Overskeid, K; Sandvei, P; Johansen, } \\
\text { A; Sognen, E; Aarskog, D; Dale, A; } \\
\text { Hegrestad, S; Reikvam, A; Hawkes, L; } \\
\text { Hoff, S; Torjussen, T; Norvik, R; } \\
\text { Jorgensen, C; Hjermann, I; Leren, P; } \\
\text { Narvestad, A; Fausa, D; Gjestvang, FT; } \\
\text { Nordland, B; Brunmark, P; Bioklund, H; } \\
\text { Bioklund, B; Forsberg, H; Bergstrom, B; } \\
\text { Laaksonen, I; Vestermark, MB; Mascher, } \\
\text { G; Hammarstrom, E; Trosell, K; } \\
\text { Karlsson, L; Hallstrom, L; Stjerna, A; } \\
\text { Slette, MK; Diderholm, E; Pberglund, K; } \\
\text { Linde, B; Ahlmark, G; Saetre, H; } \\
\text { Ahlberg, G; Sundkvist, K; Gustafsson, } \\
\text { PE; Gustafsson, E; Norrby, A; Jaup, B; } \\
\text { Svensson, L; Wiklund, O; Linden, T; } \\
\text { Bergh, CH; Jonsteg, K; Bonnier, B; } \\
\text { Lundin, Y; Romanus, K; Ulvenstam, G; } \\
\text { Johansson, S; Wallin, I; Dudas, K; } \\
\text { Andreasson, M; Torelund, G; Skarfors, } \\
\text { E; Ruter, G; Akesson, L; Wagner, F; } \\
\text { Ljungdahl, L; Wagner, V; Rasmanis, G; } \\
\text { Edhag, O; Vourisalo, D; Hjelmsell, H; } \\
\text { Wesley, G; Lundkvist, L; Angman, K; } \\
\text { Olsson, A; Svenson, O; Kuylenstierna, J; } \\
\text { Frisenettefich, K; Bergman, E; } \\
\text { Stromblad, H; Jensen, S; Jonsson, E; } \\
\text { Levin, C; Odeberg, H; Bengtsson, PO; } \\
\text { Holmesson, E; Hedstrand, H; Bojo, L; } \\
\text { Oberg, S; Leksell, H; Werner, P; Persson, } \\
\text { S; Simonsson, M; Wirenstam, UB; } \\
\text { Moberg, B; Ekstrand, AB; Nicol, P; } \\
\text { Malmros, B; Saaw, J; Arcini, N; } \\
\text { Kobosko, J; Anevik, IG; Gyland, F; } \\
\text { Lundh, B; Wennerholm, M; Olsson, C; } \\
\text { Kjellberg, J; Fabianson, K; Fraser, T; } \\
\text { Bergkvist, I; Bergdahl, B; Fluur, C; } \\
\text { Wajerstam, S; Svensson, KA; Ekholm, L; } \\
\text { Torebo, E; Ryberg, A; Frisell, JE; } \\
\text { Hedman, A; Wallrup, L; Andersen, G; } \\
\text { Sandstrom, M; Alberg, K; Fagher, B; } \\
\text { Thulin, T; Svenstam, I; Bjurman, A; } \\
\text { Skoglund, E; Dahl, G; Kjellstrom, T; } \\
\text { Juhlin, P; Sjooboquist, M; Sjogren, A; } \\
\text { Loogna, E; Jansson, T; Friden, J; }\end{array}$ & & \\
\hline
\end{tabular}


Table 1

(Continued)

\begin{tabular}{|c|c|c|c|c|c|}
\hline Rank & Year & Authors & Title & Journal & $\begin{array}{l}\text { Times } \\
\text { cited }\end{array}$ \\
\hline & & $\begin{array}{l}\text { Nilsson, O; Andersson, PO; Henriksson, } \\
\text { C; Ellstrom, J; Brodersson, H; Lundquist, } \\
\text { L; Aslund, M; Boman, K; Jansson, JH; } \\
\text { Norrfors, B; Hoglund, C; Lundblad, M; } \\
\text { Liljefors, I; Wennerstrom, L; Perz, I; } \\
\text { Leijd, B; Falkenberg, C; Bergsten, L; } \\
\text { Strom, S; Engstrom, AC; Ejdeback, J; } \\
\text { Malmberg, K; Hogstrom, S; Stahl, L; } \\
\text { Moller, BH; Lycksell, M; Soderstrom, M; } \\
\text { Hansson, E; Hallen, C; Stakebarg, H; } \\
\text { Borretzen, J; Heden, B; Andersson, K; } \\
\text { Johnson, O; Birgander, LS; Elander, B; } \\
\text { Lidell, C; Andersson, PE; Marklund, E; } \\
\text { Dahlen, M; Rucker, F; Lofqvist, M; } \\
\text { Wannberg, B; Lim, BH; Larsson, O; } \\
\text { Andersson, G; Hansson, A; Uchto, M; } \\
\text { Gowenius, M; Uggeldahl, I; Ursing, D; } \\
\text { Hammarlund, P; Nyman, P; Tsuppuka, } \\
\text { E; Malmberg, L; Goransson, K; } \\
\text { Hasselgren, P; Insberg, CM; Petterson, S; } \\
\text { Ahrlin, A; Lovheim, O; Andersson, LO; } \\
\text { Grundstrom, I }\end{array}$ & & & \\
\hline 4 & 1974 & $\begin{array}{l}\text { Allain, CC; Poon, LS; Chan, CSG; } \\
\text { Richmond, W; Fu, PC }\end{array}$ & $\begin{array}{l}\text { Enzymatic determination } \\
\text { of total serum-cholesterol }\end{array}$ & $\begin{array}{l}\text { CLINICAL } \\
\text { CHEMISTRY }\end{array}$ & 5978 \\
\hline 5 & 1989 & $\begin{array}{l}\text { Steinberg, D; Parthasarathy, S; Carew, } \\
\text { TE; Khoo, JC; Witztum, JL }\end{array}$ & $\begin{array}{l}\text { Beyond cholesterol - } \\
\text { Modifications of } \\
\text { low-density lipoprotein that } \\
\text { increase its atherogenicity }\end{array}$ & $\begin{array}{l}\text { NEW ENGLAND } \\
\text { JOURNAL OF } \\
\text { MEDICINE }\end{array}$ & 5920 \\
\hline 6 & 1996 & $\begin{array}{l}\text { Sacks, FM; Pfeffer, MA; Moye, LA; } \\
\text { Rouleau, JL; Rutherford, JD; Cole, TG; } \\
\text { Brown, L; Warnica, JW; Arnold, JMO; } \\
\text { Wun, CC; Davis, BR; Braunwald, E }\end{array}$ & $\begin{array}{l}\text { The effect of pravastatin on } \\
\text { coronary events after } \\
\text { myocardial infarction in } \\
\text { patients with average } \\
\text { cholesterol levels }\end{array}$ & $\begin{array}{l}\text { NEW ENGLAND } \\
\text { JOURNAL OF } \\
\text { MEDICINE }\end{array}$ & 4789 \\
\hline 7 & 2002 & $\begin{array}{l}\text { Collins, R; Armitage, J; Parish, S; } \\
\text { Sleight, P; Peto, R }\end{array}$ & $\begin{array}{l}\text { MRC/BHF Heart } \\
\text { Protection Study of } \\
\text { cholesterol lowering with } \\
\text { simvastatin in } 20,536 \\
\text { high-risk individuals: } \\
\text { A randomised } \\
\text { placebo-controlled trial }\end{array}$ & LANCET & 4533 \\
\hline 8 & 1986 & Brown, MS; Goldstein, JL & $\begin{array}{l}\text { A receptor-mediated } \\
\text { pathway for cholesterol } \\
\text { homeostasis }\end{array}$ & SCIENCE & 3940 \\
\hline 9 & 1952 & $\begin{array}{l}\text { Abell, LL; Levy, BB; Brodie, BB; } \\
\text { Kendall, FE }\end{array}$ & $\begin{array}{l}\text { A simplified method for the } \\
\text { estimation of total } \\
\text { cholesterol in serum and } \\
\text { demonstration of its } \\
\text { specificity }\end{array}$ & $\begin{array}{l}\text { JOURNAL OF } \\
\text { BIOLOGICAL } \\
\text { CHEMISTRY }\end{array}$ & 3630 \\
\hline
\end{tabular}


Table 1

(Continued)

\begin{tabular}{|c|c|c|c|c|c|}
\hline Rank & Year & Authors & Title & Journal & $\begin{array}{l}\text { Times } \\
\text { cited }\end{array}$ \\
\hline 10 & 1998 & $\begin{array}{l}\text { Tonkin, A; Aylward, P; Colquhoun, D; } \\
\text { Glasziou, P; Harris, P; MacMahon, S; } \\
\text { Magnus, P; Newel, D; Nestel, P; Sharpe, } \\
\text { N; Hunt, D; Shaw, J; Simes, RJ; } \\
\text { Thompson, P; Thomson, A; West, M; } \\
\text { White, H; Simes, S; Hague, W; Caleo, S; } \\
\text { Hall, J; Martin, A; Mulray, S; Barter, P; } \\
\text { Beilin, L; Collins, R; McNeil, J; Meier, } \\
\text { P; Willimott, H; Smithers, D; Wallace, P; } \\
\text { Sullivan, D; Keech, A }\end{array}$ & $\begin{array}{l}\text { Prevention of } \\
\text { cardiovascular events and } \\
\text { death with pravastatin in } \\
\text { patients with coronary } \\
\text { heart disease and a broad } \\
\text { range of initial cholesterol } \\
\text { levels }\end{array}$ & $\begin{array}{l}\text { NEW ENGLAND } \\
\text { JOURNAL OF } \\
\text { MEDICINE }\end{array}$ & 3586 \\
\hline 11 & 1998 & $\begin{array}{l}\text { Downs, JR; Clearfield, M; Weis, S; } \\
\text { Whitney, E; Shapiro, DR; Beere, PA; } \\
\text { Langendorfer, A; Stein, EA; Kruyer, W; } \\
\text { Gotto, AM }\end{array}$ & $\begin{array}{l}\text { Primary prevention of } \\
\text { acute coronary events with } \\
\text { lovastatin in men and } \\
\text { women with average } \\
\text { cholesterol levels - Results } \\
\text { of AFCAPS/TexCAPS }\end{array}$ & $\begin{array}{l}\text { JAMA-JOURNAL } \\
\text { OF THE } \\
\text { AMERICAN } \\
\text { MEDICAL } \\
\text { ASSOCIATION }\end{array}$ & 3383 \\
\hline 12 & 2004 & $\begin{array}{l}\text { Grundy, SM; Cleeman, JI; Merz, CNB; } \\
\text { Brewer, HB; Clark, LT; Hunninghake, } \\
\text { DB; Pasternak, RC; Smith, SC; Stone, NJ }\end{array}$ & $\begin{array}{l}\text { Implications of recent } \\
\text { clinical trials for the } \\
\text { National Cholesterol } \\
\text { Education Program Adult } \\
\text { Treatment Panel III } \\
\text { guidelines }\end{array}$ & CIRCULATION & 3212 \\
\hline 13 & 2005 & $\begin{array}{l}\text { Baigent, C; Keech, A; Kearney, PM; } \\
\text { Blackwell, L; Buck, G; Pollicino, C; } \\
\text { Kirby, A; Sourjina, T; Peto, R; Collins, } \\
\text { R; Simes, J }\end{array}$ & $\begin{array}{l}\text { Efficacy and safety of } \\
\text { cholesterol-lowering } \\
\text { treatment: Prospective } \\
\text { meta-analysis of data from } \\
90,056 \text { participants in } 14 \\
\text { randomised trials of statins }\end{array}$ & LANCET & 3000 \\
\hline 14 & 1988 & Mahley, RW & $\begin{array}{l}\text { Apolipoprotein-E - } \\
\text { Cholesterol transport } \\
\text { protein with expanding role } \\
\text { in cell biology }\end{array}$ & SCIENCE & 2977 \\
\hline 15 & 1953 & Zlatkis, A; Zak, B; Boyle, AJ & $\begin{array}{l}\text { A new method for the } \\
\text { direct determination of } \\
\text { serum cholesterol }\end{array}$ & $\begin{array}{l}\text { JOURNAL OF } \\
\text { LABORATORY } \\
\text { AND CLINICAL } \\
\text { MEDICINE }\end{array}$ & 2590 \\
\hline 16 & 1950 & Sperry, WM; Webb, M & $\begin{array}{l}\text { A revision of the } \\
\text { schoenheimer-sperry } \\
\text { method for cholesterol } \\
\text { determination }\end{array}$ & $\begin{array}{l}\text { JOURNAL OF } \\
\text { BIOLOGICAL } \\
\text { CHEMISTRY }\end{array}$ & 2516 \\
\hline 17 & 1968 & Glomset, JA & $\begin{array}{l}\text { Plasma lecithin - } \\
\text { Cholesterol acyltransferase } \\
\text { reaction }\end{array}$ & $\begin{array}{l}\text { JOURNAL OF } \\
\text { LIPID RESEARCH }\end{array}$ & 2227 \\
\hline
\end{tabular}


Table 1

(Continued)

\begin{tabular}{|c|c|c|c|c|c|}
\hline Rank & Year & Authors & Title & Journal & $\begin{array}{l}\text { Times } \\
\text { cited }\end{array}$ \\
\hline 18 & 1979 & $\begin{array}{l}\text { Goldstein, JL; Ho, YK; Basu, SK; } \\
\text { Brown, MS }\end{array}$ & $\begin{array}{l}\text { Binding-site on } \\
\text { macrophages that mediates } \\
\text { uptake and degradation of } \\
\text { acetylated low-density } \\
\text { lipoprotein, producing } \\
\text { massive cholesterol } \\
\text { deposition }\end{array}$ & $\begin{array}{l}\text { PROCEEDINGS } \\
\text { OF THE } \\
\text { NATIONAL } \\
\text { ACADEMY OF } \\
\text { SCIENCES OF } \\
\text { THE UNITED } \\
\text { STATES OF } \\
\text { AMERICA }\end{array}$ & 2110 \\
\hline 19 & 2002 & $\begin{array}{l}\text { Ridker, PM; Rifai, N; Rose, L; Buring, } \\
\text { JE; Cook, NR }\end{array}$ & $\begin{array}{l}\text { Comparison of C-reactive } \\
\text { protein and low-density } \\
\text { lipoprotein cholesterol } \\
\text { levels in the prediction of } \\
\text { first cardiovascular events }\end{array}$ & $\begin{array}{l}\text { NEW ENGLAND } \\
\text { JOURNAL OF } \\
\text { MEDICINE }\end{array}$ & 2060 \\
\hline 20 & 1999 & $\begin{array}{l}\text { Rubins, HB; Robins, SJ; Collins, D; Fye, } \\
\text { CL; Anderson, JW; Elam, MB; Faas, FH; } \\
\text { Linares, E; Schaefer, EJ; Schectman, G; } \\
\text { Wilt, TJ; Wittes, J }\end{array}$ & $\begin{array}{l}\text { Gemfibrozil for the } \\
\text { secondary prevention of } \\
\text { coronary heart disease in } \\
\text { men with low levels of } \\
\text { high-density lipoprotein } \\
\text { cholesterol }\end{array}$ & $\begin{array}{l}\text { NEW ENGLAND } \\
\text { JOURNAL OF } \\
\text { MEDICINE }\end{array}$ & 2055 \\
\hline 21 & 1983 & Brown, MS; Goldstein, JL & $\begin{array}{l}\text { Lipoprotein metabolism in } \\
\text { the macrophage - } \\
\text { Implications for cholesterol } \\
\text { deposition in } \\
\text { atherosclerosis }\end{array}$ & $\begin{array}{l}\text { ANNUAL REVIEW } \\
\text { OF } \\
\text { BIOCHEMISTRY }\end{array}$ & 2018 \\
\hline 22 & 2003 & $\begin{array}{l}\text { Sever, PS; Dahlof, B; Poulter, NR; } \\
\text { Wedel, H; Beevers, G; Caulfield, M; } \\
\text { Collins, R; Kjeldsen, SE; Kristinsson, A; } \\
\text { McInnes, GT; Mehlsen, J; Nieminen, M; } \\
\text { O’Brien, E; Ostergren, J }\end{array}$ & $\begin{array}{l}\text { Prevention of coronary and } \\
\text { stroke events with } \\
\text { atorvastatin in hypertensive } \\
\text { patients who have average } \\
\text { or lower-than-average } \\
\text { cholesterol concentrations, } \\
\text { in the Anglo-Scandinavian } \\
\text { Cardiac Outcomes } \\
\text { Trial-Lipid Lowering Arm } \\
\text { (ASCOT-LLA): } \\
\text { A multicentre randomised } \\
\text { controlled trial }\end{array}$ & LANCET & 2003 \\
\hline 23 & 1997 & Brown, MS; Goldstein, JL & $\begin{array}{l}\text { The SREBP pathway: } \\
\text { Regulation of cholesterol } \\
\text { metabolism by proteolysis } \\
\text { of a membrane-bound } \\
\text { transcription factor }\end{array}$ & CELL & 1990 \\
\hline 24 & 2002 & Horton, JD; Goldstein, JL; Brown, MS & $\begin{array}{l}\text { SREBPs: Activators of the } \\
\text { complete program of } \\
\text { cholesterol and fatty acid } \\
\text { synthesis in the liver }\end{array}$ & $\begin{array}{l}\text { JOURNAL OF } \\
\text { CLINICAL } \\
\text { INVESTIGATION }\end{array}$ & 1903 \\
\hline
\end{tabular}


Table 1

(Continued)

\begin{tabular}{|c|c|c|c|c|c|}
\hline Rank & Year & Authors & Title & Journal & $\begin{array}{l}\text { Times } \\
\text { cited }\end{array}$ \\
\hline 25 & 1989 & $\begin{array}{l}\text { Gordon, DJ; Probstfield, JL; Garrison, } \\
\text { RJ; Neaton, JD; Castelli, WP; Knoke, JD; } \\
\text { Jacobs, DR; Bangdiwala, S; Tyroler, HA }\end{array}$ & $\begin{array}{l}\text { High-density lipoprotein } \\
\text { cholesterol and } \\
\text { cardiovascular-disease }-4 \\
\text { prospective } \\
\text { American-studies }\end{array}$ & CIRCULATION & 1888 \\
\hline 26 & 1971 & $\begin{array}{l}\text { Kannel, WB; Castelli, WP; Gordon, T; } \\
\text { Mcnamara, PM }\end{array}$ & $\begin{array}{l}\text { Serum cholesterol, } \\
\text { lipoproteins, and risk of } \\
\text { coronary heart disease - } \\
\text { Framingham study }\end{array}$ & $\begin{array}{l}\text { ANNALS OF } \\
\text { INTERNAL } \\
\text { MEDICINE }\end{array}$ & 1884 \\
\hline 27 & 1993 & $\begin{array}{l}\text { Grundy, SM; Bilheimer, D; Chait, A; } \\
\text { Clark, LT; Denke, M; Havel, RJ; } \\
\text { Hazzard, WR; Hulley, SB; Hunninghake, } \\
\text { DB; Kreisberg, RA; Krisetherton, P; } \\
\text { Mckenney, JM; Newman, MA; Schaefer, } \\
\text { EJ; Sobel, BE; Somelofski, C; Weinstein, } \\
\text { MC; Brewer, HB; Cleeman, JI; Donato, } \\
\text { KA; Ernst, N; Hoeg, JM; Rifkind, BM; } \\
\text { Rossouw, J; Sempos, CT; Gallivan, JM; } \\
\text { Harris, MN; Quintadler, L }\end{array}$ & $\begin{array}{l}\text { Summary of the } 2 \text { nd report } \\
\text { of the national-cholesterol- } \\
\text { education-program (NCEP) } \\
\text { expert panel on detection, } \\
\text { evaluation, and treatment } \\
\text { of high blood cholesterol in } \\
\text { adults } \\
\text { (adult-treatment-panel-II) }\end{array}$ & $\begin{array}{l}\text { JAMA-JOURNAL } \\
\text { OF THE } \\
\text { AMERICAN } \\
\text { MEDICAL } \\
\text { ASSOCIATION }\end{array}$ & 1809 \\
\hline 28 & 1982 & Warnick, GR; Benderson, J; Albers, JJ & $\begin{array}{l}\text { Dextran sulfate-Mg2+ } \\
\text { precipitation procedure for } \\
\text { quantitation of } \\
\text { high-density-lipoprotein } \\
\text { cholesterol }\end{array}$ & $\begin{array}{l}\text { CLINICAL } \\
\text { CHEMISTRY }\end{array}$ & 1738 \\
\hline 29 & 1986 & $\begin{array}{l}\text { Castelli, WP; Garrison, RJ; Wilson, } \\
\text { PWF; Abbott, RD; Kalousdian, S; } \\
\text { Kannel, WB }\end{array}$ & $\begin{array}{l}\text { Incidence of coronary } \\
\text { heart-disease and } \\
\text { lipoprotein cholesterol } \\
\text { levels - The } \\
\text { Framingham-study }\end{array}$ & $\begin{array}{l}\text { JAMA-JOURNAL } \\
\text { OF THE } \\
\text { AMERICAN } \\
\text { MEDICAL } \\
\text { ASSOCIATION }\end{array}$ & 1715 \\
\hline 30 & 2000 & Brown, DA; London, E & $\begin{array}{l}\text { Structure and function of } \\
\text { sphingolipid- and } \\
\text { cholesterol-rich membrane } \\
\text { rafts }\end{array}$ & $\begin{array}{l}\text { JOURNAL OF } \\
\text { BIOLOGICAL } \\
\text { CHEMISTRY }\end{array}$ & 1638 \\
\hline 31 & 2003 & $\begin{array}{l}\text { Collins, R; Armitage, J; Parish, S; } \\
\text { Sleight, P; Peto, R }\end{array}$ & $\begin{array}{l}\text { MRC/BHF Heart } \\
\text { Protection Study of } \\
\text { cholesterol-lowering with } \\
\text { simvastatin in } 5963 \text { people } \\
\text { with diabetes: } \\
\text { A randomised } \\
\text { placebo-controlled trial }\end{array}$ & LANCET & 1584 \\
\hline 32 & 1977 & $\begin{array}{l}\text { Castelli, WP; Doyle, JT; Gordon, T; } \\
\text { Hames, CG; Hjortland, MC; Hulley, SB; } \\
\text { Kagan, A; Zukel, WJ }\end{array}$ & $\begin{array}{l}\text { HDL cholesterol and other } \\
\text { lipids in coronary } \\
\text { heart-disease - Cooperative } \\
\text { lipoprotein phenotyping } \\
\text { study }\end{array}$ & CIRCULATION & 1513 \\
\hline
\end{tabular}


Table 1

(Continued)

\begin{tabular}{|c|c|c|c|c|c|}
\hline Rank & Year & Authors & Title & Journal & $\begin{array}{l}\text { Times } \\
\text { cited }\end{array}$ \\
\hline 33 & 1986 & Stamler, J; Wentworth, D; Neaton, JD & $\begin{array}{l}\text { Is relationship between } \\
\text { serum-cholesterol and risk } \\
\text { of premature death from } \\
\text { coronary heart-disease } \\
\text { continuous and graded - } \\
\text { Findings in } 356,222 \\
\text { primary screenees of the } \\
\text { Multiple Risk Factor } \\
\text { Intervention Trial (MRFIT) }\end{array}$ & $\begin{array}{l}\text { JAMA-JOURNAL } \\
\text { OF THE } \\
\text { AMERICAN } \\
\text { MEDICAL } \\
\text { ASSOCIATION }\end{array}$ & 1448 \\
\hline 34 & 1980 & $\begin{array}{l}\text { Alberts, AW; Chen, J; Kuron, G; Hunt, } \\
\text { V; Huff, J; Hoffman, C; Rothrock, J; } \\
\text { Lopez, M; Joshua, H; Harris, E; Patchett, } \\
\text { A; Monaghan, R; Currie, S; Stapley, E; } \\
\text { Albersschonberg, G; Hensens, O; } \\
\text { Hirshfield, J; Hoogsteen, K; Liesch, J; } \\
\text { Springer, J }\end{array}$ & $\begin{array}{l}\text { Mevinolin - A highly } \\
\text { potent competitive inhibitor } \\
\text { of hydroxymethylglutaryl- } \\
\text { coenzyme-A reductase and } \\
\text { a cholesterol-lowering } \\
\text { agent }\end{array}$ & $\begin{array}{l}\text { PROCEEDINGS } \\
\text { OF THE } \\
\text { NATIONAL } \\
\text { ACADEMY OF } \\
\text { SCIENCES OF } \\
\text { THE UNITED } \\
\text { STATES OF } \\
\text { AMERICA- } \\
\text { BIOLOGICAL } \\
\text { SCIENCES }\end{array}$ & 1337 \\
\hline 35 & 1977 & $\begin{array}{l}\text { Lopesvirella, MF; Stone, P; Ellis, S; } \\
\text { Colwell, JA }\end{array}$ & $\begin{array}{l}\text { Cholesterol determination } \\
\text { in high-density lipoproteins } \\
\text { separated by } 3 \text { different } \\
\text { methods }\end{array}$ & $\begin{array}{l}\text { CLINICAL } \\
\text { CHEMISTRY }\end{array}$ & 1292 \\
\hline 36 & 1965 & $\begin{array}{l}\text { Hegsted, DM; Mcgandy, RB; Myers, } \\
\text { ML; Stare, FJ }\end{array}$ & $\begin{array}{l}\text { Quantitative effects of } \\
\text { dietary fat on serum } \\
\text { cholesterol in man }\end{array}$ & $\begin{array}{l}\text { AMERICAN } \\
\text { JOURNAL OF } \\
\text { CLINICAL } \\
\text { NUTRITION }\end{array}$ & 1245 \\
\hline 37 & 1997 & $\begin{array}{l}\text { Delmas, PD; Bjarnason, NH; Mitlak, } \\
\text { BH; Ravoux, AC; Shah, AS; Huster, WJ; } \\
\text { Draper, M; Christiansen, C }\end{array}$ & $\begin{array}{l}\text { Effects of raloxifene on } \\
\text { bone mineral density, } \\
\text { serum cholesterol } \\
\text { concentrations, and uterine } \\
\text { endometrium in } \\
\text { postmenopausal women }\end{array}$ & $\begin{array}{l}\text { NEW ENGLAND } \\
\text { JOURNAL OF } \\
\text { MEDICINE }\end{array}$ & 1201 \\
\hline 38 & 1978 & Warnick, GR; Albers, JJ & $\begin{array}{l}\text { Comprehensive evaluation } \\
\text { of heparin-manganese } \\
\text { precipitation procedure for } \\
\text { estimating high-density } \\
\text { lipoprotein cholesterol }\end{array}$ & $\begin{array}{l}\text { JOURNAL OF } \\
\text { LIPID RESEARCH }\end{array}$ & 1191 \\
\hline 39 & 2010 & $\begin{array}{l}\text { Baigent, C; Blackwell, L; Emberson, J; } \\
\text { Holland, LE; Reith, C; Bhala, N; Peto, R; } \\
\text { Barnes, EH; Keech, A; Simes, J; } \\
\text { Collins, R }\end{array}$ & $\begin{array}{l}\text { Efficacy and safety of more } \\
\text { intensive lowering of LDL } \\
\text { cholesterol: } \\
\text { A meta-analysis of data } \\
\text { from } 170,000 \text { participants } \\
\text { in } 26 \text { randomised trials }\end{array}$ & LANCET & 1180 \\
\hline 40 & 1979 & Kannel, WB; Castelli, WP; Gordon, T & $\begin{array}{l}\text { Cholesterol in the } \\
\text { prediction of } \\
\text { atherosclerotic disease - } \\
\text { New perspectives based on } \\
\text { the framingham study }\end{array}$ & $\begin{array}{l}\text { ANNALS OF } \\
\text { INTERNAL } \\
\text { MEDICINE }\end{array}$ & 1161 \\
\hline
\end{tabular}


Table 1

(Continued)

\begin{tabular}{|c|c|c|c|c|c|}
\hline Rank & Year & Authors & Title & Journal & $\begin{array}{c}\text { Times } \\
\text { cited }\end{array}$ \\
\hline 41 & 1995 & Fielding, CJ; Fielding, PE & $\begin{array}{l}\text { Molecular physiology of } \\
\text { reverse cholesterol } \\
\text { transport }\end{array}$ & $\begin{array}{l}\text { JOURNAL OF } \\
\text { LIPID RESEARCH }\end{array}$ & 1159 \\
\hline 42 & 1968 & Admirand, WH; Small, DM & $\begin{array}{l}\text { Physicochemical basis of } \\
\text { cholesterol gallstone } \\
\text { formation in man }\end{array}$ & $\begin{array}{l}\text { JOURNAL OF } \\
\text { CLINICAL } \\
\text { INVESTIGATION }\end{array}$ & 1114 \\
\hline 43 & 1997 & $\begin{array}{l}\text { Pyorala, K; Pedersen, TR; Kjekshus, J; } \\
\text { Faergeman, O; Olsson, AG; } \\
\text { Thorgeirsson, G }\end{array}$ & $\begin{array}{l}\text { Cholesterol lowering with } \\
\text { simvastatin improves } \\
\text { prognosis of diabetic } \\
\text { patients with coronary } \\
\text { heart disease - A subgroup } \\
\text { analysis of the } \\
\text { Scandinavian Simvastatin } \\
\text { Survival Study (4S) }\end{array}$ & DIABETES CARE & 1113 \\
\hline 44 & 1985 & Yeagle, PL & $\begin{array}{l}\text { Cholesterol and the } \\
\text { cell-membrane }\end{array}$ & $\begin{array}{l}\text { BIOCHIMICA ET } \\
\text { BIOPHYSICA } \\
\text { ACTA }\end{array}$ & 1079 \\
\hline 45 & 1976 & $\begin{array}{l}\text { Basu, SK; Goldstein, JL; Anderson, } \\
\text { RGW; Brown, MS }\end{array}$ & $\begin{array}{l}\text { Degradation of cationized } \\
\text { low-density lipoprotein and } \\
\text { regulation of } \\
\text { cholesterol-metabolism in } \\
\text { homozygous familial } \\
\text { hypercholesterolemia } \\
\text { fibroblasts }\end{array}$ & $\begin{array}{l}\text { PROCEEDINGS } \\
\text { OF THE } \\
\text { NATIONAL } \\
\text { ACADEMY OF } \\
\text { SCIENCES OF } \\
\text { THE UNITED } \\
\text { STATES OF } \\
\text { AMERICA }\end{array}$ & 1071 \\
\hline 46 & 1934 & Schoenheimer, R; Sperry, WM & $\begin{array}{l}\text { A micromethod for the } \\
\text { determination of free and } \\
\text { combined cholesterol }\end{array}$ & $\begin{array}{l}\text { JOURNAL OF } \\
\text { BIOLOGICAL } \\
\text { CHEMISTRY }\end{array}$ & 1068 \\
\hline 47 & 1995 & $\begin{array}{l}\text { Treasure, CB; Klein, JL; Weintraub, WS; } \\
\text { Talley, JD; Stillabower, ME; Kosinski, } \\
\text { AS; Zhang, J; Boccuzzi, SJ; Cedarholm, } \\
\text { JC; Alexander, RW }\end{array}$ & $\begin{array}{l}\text { Beneficial-effects of } \\
\text { cholesterol-lowering } \\
\text { therapy on the coronary } \\
\text { endothelium in patients } \\
\text { with coronary-artery } \\
\text { disease }\end{array}$ & $\begin{array}{l}\text { NEW ENGLAND } \\
\text { JOURNAL OF } \\
\text { MEDICINE }\end{array}$ & 1010 \\
\hline 48 & 1959 & Friedman, M; Rosenman, RH & $\begin{array}{l}\text { Association of specific } \\
\text { overt behavior pattern with } \\
\text { blood and cardiovascular } \\
\text { findings - Blood } \\
\text { cholesterol level, blood } \\
\text { clotting time, incidence of } \\
\text { arcus senilis, and clinical } \\
\text { coronary artery disease }\end{array}$ & $\begin{array}{l}\text { JAMA-JOURNAL } \\
\text { OF THE } \\
\text { AMERICAN } \\
\text { MEDICAL } \\
\text { ASSOCIATION }\end{array}$ & 1008 \\
\hline 49 & 1974 & Roschlau, P; Bernt, E; Gruber, W & $\begin{array}{l}\text { Enzymatic determination } \\
\text { of total cholesterol in } \\
\text { serum }\end{array}$ & $\begin{array}{l}\text { ZEITSCHRIFT } \\
\text { FUR KLINISCHE } \\
\text { CHEMIE UND } \\
\text { KLINISCHE } \\
\text { BIOCHEMIE }\end{array}$ & 985 \\
\hline
\end{tabular}


Table 1

(Continued)

\begin{tabular}{|c|c|c|c|c|c|}
\hline Rank & Year & Authors & Title & Journal & $\begin{array}{l}\text { Times } \\
\text { cited }\end{array}$ \\
\hline 50 & 1973 & Richmond, W & $\begin{array}{l}\text { Preparation and properties } \\
\text { of a cholesterol oxidase } \\
\text { from nocardia sp. and its } \\
\text { application to enzymatic } \\
\text { assay of total cholesterol in } \\
\text { serum }\end{array}$ & $\begin{array}{l}\text { CLINICAL } \\
\text { CHEMISTRY }\end{array}$ & 946 \\
\hline 51 & 2003 & $\begin{array}{l}\text { Mensink, RP; Zock, PL; Kester, ADM; } \\
\text { Katan, MB }\end{array}$ & $\begin{array}{l}\text { Effects of dietary fatty } \\
\text { acids and carbohydrates on } \\
\text { the ratio of serum total to } \\
\text { HDL cholesterol and on } \\
\text { serum lipids and } \\
\text { apolipoproteins: } \\
\text { A meta-analysis of } 60 \\
\text { controlled trials }\end{array}$ & $\begin{array}{l}\text { AMERICAN } \\
\text { JOURNAL OF } \\
\text { CLINICAL } \\
\text { NUTRITION }\end{array}$ & 937 \\
\hline 51 & 2000 & $\begin{array}{l}\text { Berge, KE; Tian, H; Graf, GA; Yu, LQ; } \\
\text { Grishin, NV; Schultz, J; Kwiterovich, P; } \\
\text { Shan, B; Barnes, R; Hobbs, HH }\end{array}$ & $\begin{array}{l}\text { Accumulation of dietary } \\
\text { cholesterol in } \\
\text { sitosterolemia caused by } \\
\text { mutations in adjacent ABC } \\
\text { transporters }\end{array}$ & SCIENCE & 937 \\
\hline 53 & 1992 & $\begin{array}{l}\text { Manninen, V; Tenkanen, L; Koskinen, P; } \\
\text { Huttunen, JK; Manttari, M; Heinonen, } \\
\text { OP; Frick, MH }\end{array}$ & $\begin{array}{l}\text { Joint effects of serum } \\
\text { triglyceride and LDL } \\
\text { cholesterol and HDL } \\
\text { cholesterol concentrations } \\
\text { on coronary heart-disease } \\
\text { risk in the Helsinki } \\
\text { heart-study - Implications } \\
\text { for treatment }\end{array}$ & CIRCULATION & 925 \\
\hline 54 & 1986 & $\begin{array}{l}\text { Martin, MJ; Browner, WS; Wentworth, } \\
\text { D; Hulley, SB; Kuller, LH }\end{array}$ & $\begin{array}{l}\text { Serum-cholesterol, } \\
\text { blood-pressure, and } \\
\text { mortality - Implications } \\
\text { from a cohort of } 361,662 \\
\text { men }\end{array}$ & LANCET & 919 \\
\hline 55 & 1998 & $\begin{array}{l}\text { Peet, DJ; Turley, SD; Ma, WZ; Janowski, } \\
\text { BA; Lobaccaro, JMA; Hammer, RE; } \\
\text { Mangelsdorf, DJ }\end{array}$ & $\begin{array}{l}\text { Cholesterol and bile acid } \\
\text { metabolism are impaired in } \\
\text { mice lacking the nuclear } \\
\text { oxysterol receptor LXR } \\
\text { alpha }\end{array}$ & CELL & 918 \\
\hline 56 & 1973 & Rudel, LL; Morris, MD & $\begin{array}{l}\text { Determination of } \\
\text { cholesterol using } \\
\text { ortho-phthalaldehyde }\end{array}$ & $\begin{array}{l}\text { JOURNAL OF } \\
\text { LIPID RESEARCH }\end{array}$ & 917 \\
\hline 57 & 1998 & $\begin{array}{l}\text { Ridker, PM; Rifai, N; Pfeffer, MA; } \\
\text { Sacks, FM; Moye, LA; Goldman, S; } \\
\text { Flaker, GC; Braunwald, E }\end{array}$ & $\begin{array}{l}\text { Inflammation, pravastatin, } \\
\text { and the risk of coronary } \\
\text { events after myocardial } \\
\text { infarction in patients with } \\
\text { average cholesterol levels }\end{array}$ & CIRCULATION & 897 \\
\hline 58 & 2000 & $\begin{array}{l}\text { Repa, JJ; Turley, SD; Lobaccaro, JMA; } \\
\text { Medina, J; Li, L; Lustig, K; Shan, B; } \\
\text { Heyman, RA; Dietschy, JM; } \\
\text { Mangelsdorf, DJ }\end{array}$ & $\begin{array}{l}\text { Regulation of absorption } \\
\text { and ABC1-mediated efflux } \\
\text { of cholesterol by RXR } \\
\text { heterodimers }\end{array}$ & SCIENCE & 888 \\
\hline
\end{tabular}


Table 1

(Continued)

\begin{tabular}{|c|c|c|c|c|c|}
\hline Rank & Year & Authors & Title & Journal & $\begin{array}{l}\text { Times } \\
\text { cited }\end{array}$ \\
\hline 59 & 1995 & $\begin{array}{l}\text { Anderson, TJ; Meredith, IT; Yeung, AC; } \\
\text { Frei, B; Selwyn, AP; Ganz, P }\end{array}$ & $\begin{array}{l}\text { The effect of } \\
\text { cholesterol-lowering and } \\
\text { antioxidant therapy on } \\
\text { endothelium-dependent } \\
\text { coronary vasomotion }\end{array}$ & $\begin{array}{l}\text { NEW ENGLAND } \\
\text { JOURNAL OF } \\
\text { MEDICINE }\end{array}$ & 883 \\
\hline 60 & 1972 & Carlson, LA; Bottiger, LE & $\begin{array}{l}\text { Ischemic heart-disease in } \\
\text { relation to fasting values of } \\
\text { plasma triglycerides and } \\
\text { cholesterol - Stockholm } \\
\text { prospective study }\end{array}$ & LANCET & 867 \\
\hline 61 & 1991 & $\begin{array}{l}\text { Stampfer, MJ; Sacks, FM; Salvini, S; } \\
\text { Willett, WC; Hennekens, CH }\end{array}$ & $\begin{array}{l}\text { A prospective-study of } \\
\text { cholesterol, } \\
\text { apolipoproteins, and the } \\
\text { risk of } \\
\text { myocardial-infarction }\end{array}$ & $\begin{array}{l}\text { NEW ENGLAND } \\
\text { JOURNAL OF } \\
\text { MEDICINE }\end{array}$ & 865 \\
\hline 62 & 1998 & $\begin{array}{l}\text { Simons, M; Keller, P; De Strooper, B; } \\
\text { Beyreuther, K; Dotti, CG; Simons, K }\end{array}$ & $\begin{array}{l}\text { Cholesterol depletion } \\
\text { inhibits the generation of } \\
\text { beta-amyloid in } \\
\text { hippocampal neurons }\end{array}$ & $\begin{array}{l}\text { PROCEEDINGS } \\
\text { OF THE } \\
\text { NATIONAL } \\
\text { ACADEMY OF } \\
\text { SCIENCES OF } \\
\text { THE UNITED } \\
\text { STATES OF } \\
\text { AMERICA }\end{array}$ & 859 \\
\hline 63 & 1999 & Brown, MS; Goldstein, JL & $\begin{array}{l}\text { A proteolytic pathway that } \\
\text { controls the cholesterol } \\
\text { content of membranes, } \\
\text { cells, and blood }\end{array}$ & $\begin{array}{l}\text { PROCEEDINGS } \\
\text { OF THE } \\
\text { NATIONAL } \\
\text { ACADEMY OF } \\
\text { SCIENCES OF } \\
\text { THE UNITED } \\
\text { STATES OF } \\
\text { AMERICA }\end{array}$ & 853 \\
\hline 64 & 1994 & Law, MR; Wald, NJ; Thompson, SG & $\begin{array}{l}\text { By how much and how } \\
\text { quickly does reduction in } \\
\text { serum-cholesterol } \\
\text { concentration lower risk of } \\
\text { ischemic-heart-disease }\end{array}$ & $\begin{array}{l}\text { BRITISH } \\
\text { MEDICAL } \\
\text { JOURNAL }\end{array}$ & 848 \\
\hline 65 & 1990 & Vist, MR; Davis, JH & $\begin{array}{l}\text { Phase-equilibria of } \\
\text { cholesterol dipalmi- } \\
\text { toylphosphatidylcholine } \\
\text { mixtures - H-2 nuclear } \\
\text { magnetic-resonance and } \\
\text { differential scanning } \\
\text { calorimetry }\end{array}$ & BIOCHEMISTRY & 842 \\
\hline 66 & 2004 & $\begin{array}{l}\text { Altmann, SW; Davis, HR; Zhu, LJ; Yao, } \\
\text { XR; Hoos, LM; Tetzloff, G; Iyer, SPN; } \\
\text { Maguire, M; Golovko, A; Zeng, M; } \\
\text { Wang, LQ; Murgolo, N; Graziano, MP }\end{array}$ & $\begin{array}{l}\text { Niemann-Pick C1 like } 1 \\
\text { protein is critical for } \\
\text { intestinal cholesterol } \\
\text { absorption }\end{array}$ & SCIENCE & 828 \\
\hline 67 & 1981 & Brown, MS; Kovanen, PT; Goldstein, JL & $\begin{array}{l}\text { Regulation of } \\
\text { plasma-cholesterol by } \\
\text { lipoprotein receptors }\end{array}$ & SCIENCE & 825 \\
\hline
\end{tabular}


Table 1

(Continued)

\begin{tabular}{|c|c|c|c|c|c|}
\hline Rank & Year & Authors & Title & Journal & $\begin{array}{l}\text { Times } \\
\text { cited }\end{array}$ \\
\hline 68 & 1990 & Mensink, RP; Katan, MB & $\begin{array}{l}\text { Effect of dietary } \\
\text { trans-fatty-acids on } \\
\text { high-density and } \\
\text { low-density-lipoprotein } \\
\text { cholesterol levels in } \\
\text { healthy-subjects }\end{array}$ & $\begin{array}{l}\text { NEW ENGLAND } \\
\text { JOURNAL OF } \\
\text { MEDICINE }\end{array}$ & 821 \\
\hline 69 & 1976 & Brown, MS; Goldstein, JL & $\begin{array}{l}\text { Receptor-mediated control } \\
\text { of cholesterol-metabolism }\end{array}$ & SCIENCE & 815 \\
\hline 70 & 1997 & $\begin{array}{l}\text { Carstea, ED; Morris, JA; Coleman, KG; } \\
\text { Loftus, SK; Zhang, D; Cummings, C; } \\
\text { Gu, J; Rosenfeld, MA; Pavan, WJ; } \\
\text { Krizman, DB; Nagle, J; Polymeropoulos, } \\
\text { MH; Sturley, SL; Ioannou, YA; Higgins, } \\
\text { ME; Comly, M; Cooney, A; Brown, A; } \\
\text { Kaneski, CR; BlanchetteMackie, EJ; } \\
\text { Dwyer, NK; Neufeld, EB; Chang, TY; } \\
\text { Liscum, L; Strauss, JF; Ohno, K; Zeigler, } \\
\text { M; Carmi, R; Sokol, J; Markie, D; } \\
\text { ONeill, RR; vanDiggelen, OP; Elleder, } \\
\text { M; Patterson, MC; Brady, RO; Vanier, } \\
\text { MT; Pentchev, PG; Tagle, DA }\end{array}$ & $\begin{array}{l}\text { Niemann-Pick } \mathrm{C} 1 \text { disease } \\
\text { gene: Homology to } \\
\text { mediators of cholesterol } \\
\text { homeostasis }\end{array}$ & SCIENCE & 797 \\
\hline 70 & 1996 & Porter, JA; Young, KE; Beachy, PA & $\begin{array}{l}\text { Cholesterol modification of } \\
\text { hedgehog signaling } \\
\text { proteins in animal } \\
\text { development }\end{array}$ & SCIENCE & 797 \\
\hline 72 & 1983 & $\begin{array}{l}\text { Siedel, J; Hagele, EO; Ziegenhorn, J; } \\
\text { Wahlefeld, AW }\end{array}$ & $\begin{array}{l}\text { Reagent for the enzymatic } \\
\text { determination of serum } \\
\text { total cholesterol with } \\
\text { improved lipolytic } \\
\text { efficiency }\end{array}$ & $\begin{array}{l}\text { CLINICAL } \\
\text { CHEMISTRY }\end{array}$ & 792 \\
\hline 73 & 2003 & Law, MR; Wald, NJ; Rudnicka, AR & $\begin{array}{l}\text { Quantifying effect of } \\
\text { statins on low density } \\
\text { lipoprotein cholesterol, } \\
\text { ischaemic heart disease, } \\
\text { and stroke: Systematic } \\
\text { review and meta-analysis }\end{array}$ & $\begin{array}{l}\text { BRITISH } \\
\text { MEDICAL } \\
\text { JOURNAL }\end{array}$ & 786 \\
\hline 74 & 2001 & $\begin{array}{l}\text { Chawla, A; Boisvert, WA; Lee, CH; } \\
\text { Laffitte, BA; Barak, Y; Joseph, SB; Liao, } \\
\text { D; Nagy, L; Edwards, PA; Curtiss, LK; } \\
\text { Evans, RM; Tontonoz, P }\end{array}$ & $\begin{array}{l}\text { A PPAR } \\
\text { gamma-LXR-ABCA1 } \\
\text { pathway in macrophages is } \\
\text { involved in cholesterol } \\
\text { efflux and atherogenesis }\end{array}$ & $\begin{array}{l}\text { MOLECULAR } \\
\text { CELL }\end{array}$ & 785 \\
\hline 74 & 1990 & $\begin{array}{l}\text { Muldoon, MF; Manuck, SB; Matthews, } \\
\text { KA }\end{array}$ & $\begin{array}{l}\text { Lowering cholesterol } \\
\text { concentrations and } \\
\text { mortality: A quantitative } \\
\text { review of primary } \\
\text { prevention trials }\end{array}$ & $\begin{array}{l}\text { BRITISH } \\
\text { MEDICAL } \\
\text { JOURNAL }\end{array}$ & 785 \\
\hline 76 & 1968 & $\begin{array}{l}\text { Ladbrook, BD; Williams, RM; Chapman, } \\
\text { D }\end{array}$ & $\begin{array}{l}\text { Studies on } \\
\text { lecithin-cholesterol-water } \\
\text { interactions by differential } \\
\text { scanning calorimetry and } \\
\text { X-ray diffraction }\end{array}$ & $\begin{array}{l}\text { BIOCHIMICA ET } \\
\text { BIOPHYSICA } \\
\text { ACTA }\end{array}$ & 783 \\
\hline
\end{tabular}


Table 1

(Continued)

\begin{tabular}{|c|c|c|c|c|c|}
\hline Rank & Year & Authors & Title & Journal & $\begin{array}{l}\text { Times } \\
\text { cited }\end{array}$ \\
\hline 77 & 1987 & Anderson, KM; Castelli, WP; Levy, D & $\begin{array}{l}\text { Cholesterol and mortality - } \\
30 \text { years of follow-up from } \\
\text { the framingham-study }\end{array}$ & $\begin{array}{l}\text { JAMA-JOURNAL } \\
\text { OF THE } \\
\text { AMERICAN } \\
\text { MEDICAL } \\
\text { ASSOCIATION }\end{array}$ & 781 \\
\hline 78 & 1973 & Papahadj, D; Jacobson, K; Nir, S; Isac, T & $\begin{array}{l}\text { Phase-transitions in } \\
\text { phospholipid vesicles - } \\
\text { Fluorescence polarization } \\
\text { and permeability } \\
\text { measurements concerning } \\
\text { effect of temperature and } \\
\text { cholesterol }\end{array}$ & $\begin{array}{l}\text { BIOCHIMICA ET } \\
\text { BIOPHYSICA } \\
\text { ACTA }\end{array}$ & 780 \\
\hline 79 & 1965 & Keys, A; Anderson, JT; Grande, F & $\begin{array}{l}\text { Serum cholesterol response } \\
\text { to changes in diet. } 4 \text {. } \\
\text { particular saturated fatty } \\
\text { acids in diet }\end{array}$ & METABOLISM & 772 \\
\hline 80 & 2000 & Simons, K; Ikonen, E & $\begin{array}{l}\text { Cell biology - How cells } \\
\text { handle cholesterol }\end{array}$ & SCIENCE & 766 \\
\hline 81 & 2005 & $\begin{array}{l}\text { Nissen, SE; Tuzcu, EM; Schoenhagen, P; } \\
\text { Crowe, T; Sasiela, WJ; Tsai, J; Orazem, } \\
\text { J; Magorien, RD; O’Shaughnessy, C; } \\
\text { Ganz, P }\end{array}$ & $\begin{array}{l}\text { Statin therapy, LDL } \\
\text { cholesterol, C-reactive } \\
\text { protein, and coronary } \\
\text { artery disease }\end{array}$ & $\begin{array}{l}\text { NEW ENGLAND } \\
\text { JOURNAL OF } \\
\text { MEDICINE }\end{array}$ & 761 \\
\hline 81 & 1991 & $\begin{array}{l}\text { Kazlauskas, RJ; Weissfloch, ANE; } \\
\text { Rappaport, AT; Cuccia, LA }\end{array}$ & $\begin{array}{l}\text { A rule to predict which } \\
\text { enantiomer of a secondary } \\
\text { alcohol reacts faster in } \\
\text { reactions catalyzed by } \\
\text { cholesterol esterase, lipase } \\
\text { from } \\
\text { pseudomonas-cepacia, and } \\
\text { lipase from candida-rugosa }\end{array}$ & $\begin{array}{l}\text { JOURNAL OF } \\
\text { ORGANIC } \\
\text { CHEMISTRY }\end{array}$ & 761 \\
\hline 83 & 2007 & $\begin{array}{l}\text { Lewington, S; Whitlock, G; Clarke, R; } \\
\text { Sherliker, P; Emberson, J; Halsey, J; } \\
\text { Qizilbash, N; Peto, R; Collins, R }\end{array}$ & $\begin{array}{l}\text { Blood cholesterol and } \\
\text { vascular mortality by age, } \\
\text { sex, and blood pressure: } \\
\text { A meta-analysis of } \\
\text { individual data from } 61 \\
\text { prospective studies with } \\
55,000 \text { vascular deaths }\end{array}$ & LANCET & 758 \\
\hline 84 & 2010 & $\begin{array}{l}\text { Duewell, P; Kono, H; Rayner, KJ; Sirois, } \\
\text { CM; Vladimer, G; Bauernfeind, FG; } \\
\text { Abela, GS; Franchi, L; Nunez, G; } \\
\text { Schnurr, M; Espevik, T; Lien, E; } \\
\text { Fitzgerald, KA; Rock, KL; Moore, KJ; } \\
\text { Wright, SD; Hornung, V; Latz, E }\end{array}$ & $\begin{array}{l}\text { NLRP3 inflammasomes are } \\
\text { required for atherogenesis } \\
\text { and activated by cholesterol } \\
\text { crystals }\end{array}$ & NATURE & 757 \\
\hline 84 & 2001 & $\begin{array}{l}\text { Mauch, DH; Nagler, K; Schumacher, S; } \\
\text { Goritz, C; Muller, EC; Otto, A; Pfrieger, } \\
\text { FW }\end{array}$ & $\begin{array}{l}\text { CNS synaptogenesis } \\
\text { promoted by glia-derived } \\
\text { cholesterol }\end{array}$ & SCIENCE & 757 \\
\hline 86 & 2011 & $\begin{array}{l}\text { Boden, WE; Probstfield, JL; Anderson, } \\
\text { T; Chaitman, BR; Desvignes-Nickens, P; } \\
\text { Koprowicz, K; McBride, R; Teo, K; } \\
\text { Weintraub, W }\end{array}$ & $\begin{array}{l}\text { Niacin in Patients with } \\
\text { Low HDL Cholesterol } \\
\text { Levels Receiving Intensive } \\
\text { Statin Therapy }\end{array}$ & $\begin{array}{l}\text { NEW ENGLAND } \\
\text { JOURNAL OF } \\
\text { MEDICINE }\end{array}$ & 755 \\
\hline
\end{tabular}


Table 1

(Continued)

\begin{tabular}{|c|c|c|c|c|c|}
\hline Rank & Year & Authors & Title & Journal & $\begin{array}{l}\text { Times } \\
\text { cited }\end{array}$ \\
\hline 86 & 1957 & Zak, B & $\begin{array}{l}\text { Simple rapid microtechnic } \\
\text { for serum total cholesterol }\end{array}$ & $\begin{array}{l}\text { AMERICAN } \\
\text { JOURNAL OF } \\
\text { CLINICAL } \\
\text { PATHOLOGY }\end{array}$ & 755 \\
\hline 88 & 2001 & $\begin{array}{l}\text { Oliver, WR; Shenk, JL; Snaith, MR; } \\
\text { Russell, CS; Plunket, KD; Bodkin, NL; } \\
\text { Lewis, MC; Winegar, DA; Sznaidman, } \\
\text { ML; Lambert, MH; Xu, HE; Sternbach, } \\
\text { DD; Kliewer, SA; Hansen, BC; Willson, } \\
\text { TM }\end{array}$ & $\begin{array}{l}\text { A selective peroxisome } \\
\text { proliferator-activated } \\
\text { receptor delta agonist } \\
\text { promotes reverse } \\
\text { cholesterol transport }\end{array}$ & $\begin{array}{l}\text { PROCEEDINGS } \\
\text { OF THE } \\
\text { NATIONAL } \\
\text { ACADEMY OF } \\
\text { SCIENCES OF } \\
\text { THE UNITED } \\
\text { STATES OF } \\
\text { AMERICA }\end{array}$ & 753 \\
\hline 89 & 1978 & Carey, MC & $\begin{array}{l}\text { Critical tables for } \\
\text { calculating cholesterol } \\
\text { saturation of native bile }\end{array}$ & $\begin{array}{l}\text { JOURNAL OF } \\
\text { LIPID RESEARCH }\end{array}$ & 750 \\
\hline 90 & 1999 & $\begin{array}{l}\text { Brown, L; Rosner, B; Willett, WW; } \\
\text { Sacks, FM }\end{array}$ & $\begin{array}{l}\text { Cholesterol-lowering } \\
\text { effects of dietary fiber: } \\
\text { A meta-analysis }\end{array}$ & $\begin{array}{l}\text { AMERICAN } \\
\text { JOURNAL OF } \\
\text { CLINICAL } \\
\text { NUTRITION }\end{array}$ & 737 \\
\hline 91 & 2000 & $\begin{array}{l}\text { Pearson, TA; Laurora, I; Chu, H; } \\
\text { Kafonek, S }\end{array}$ & $\begin{array}{l}\text { The Lipid Treatment } \\
\text { Assessment Project } \\
\text { (L-TAP) - A multicenter } \\
\text { survey to evaluate the } \\
\text { percentages of } \\
\text { dyslipidemic, patients } \\
\text { receiving lipid-lowering } \\
\text { therapy and achieving } \\
\text { low-density lipoprotein } \\
\text { cholesterol goals }\end{array}$ & $\begin{array}{l}\text { ARCHIVES OF } \\
\text { INTERNAL } \\
\text { MEDICINE }\end{array}$ & 725 \\
\hline 92 & 1953 & Pearson, S; Stern, S; Mcgavack, TH & $\begin{array}{l}\text { A rapid, accurate method } \\
\text { for the determination of } \\
\text { total cholesterol in serum }\end{array}$ & $\begin{array}{l}\text { ANALYTICAL } \\
\text { CHEMISTRY }\end{array}$ & 724 \\
\hline 93 & 1983 & Mahley, RW; Innerarity, TL & $\begin{array}{l}\text { Lipoprotein receptors and } \\
\text { cholesterol homeostasis }\end{array}$ & $\begin{array}{l}\text { BIOCHIMICA ET } \\
\text { BIOPHYSICA } \\
\text { ACTA }\end{array}$ & 722 \\
\hline 94 & 2001 & Ridker, PM; Stampfer, MJ; Rifai, N & $\begin{array}{l}\text { Novel risk factors for } \\
\text { systemic atherosclerosis - } \\
\text { A comparison of C-reactive } \\
\text { protein, fibrinogen, } \\
\text { homocysteine, } \\
\text { lipoprotein(a), and standard } \\
\text { cholesterol screening as } \\
\text { predictors of peripheral } \\
\text { arterial disease }\end{array}$ & $\begin{array}{l}\text { JAMA-JOURNAL } \\
\text { OF THE } \\
\text { AMERICAN } \\
\text { MEDICAL } \\
\text { ASSOCIATION }\end{array}$ & 719 \\
\hline 95 & 1989 & $\begin{array}{l}\text { Iso, H; Jacobs, DR; Wentworth, D; } \\
\text { Neaton, JD; Cohen, JD }\end{array}$ & $\begin{array}{l}\text { Serum-cholesterol levels } \\
\text { and 6-year mortality from } \\
\text { stroke in } 350,977 \text { men } \\
\text { screened for the multiple } \\
\text { risk factor intervention trial }\end{array}$ & $\begin{array}{l}\text { NEW ENGLAND } \\
\text { JOURNAL OF } \\
\text { MEDICINE }\end{array}$ & 717 \\
\hline
\end{tabular}


Table 1

(Continued)

\begin{tabular}{|c|c|c|c|c|c|}
\hline Rank & Year & Authors & Title & Journal & $\begin{array}{l}\text { Times } \\
\text { cited }\end{array}$ \\
\hline 96 & 2008 & $\begin{array}{l}\text { Kathiresan, S; Melander, O; Guiducci, C; } \\
\text { Surti, A; Burtt, NP; Rieder, MJ; Cooper, } \\
\text { GM; Roos, C; Voight, BF; Havulinna, } \\
\text { AS; Wahlstrand, B; Hedner, T; Corella, } \\
\text { D; Tai, ES; Ordovas, JM; Berglund, G; } \\
\text { Vartiainen, E; Jousilahti, P; Hedblad, B; } \\
\text { Taskinen, MR; Newton-Cheh, C; } \\
\text { Salomaa, V; Peltonen, L; Groop, L; } \\
\text { Altshuler, DM; Orho-Melander, M }\end{array}$ & $\begin{array}{l}\text { Six new loci associated } \\
\text { with blood low-density } \\
\text { lipoprotein cholesterol, } \\
\text { high-density lipoprotein } \\
\text { cholesterol or triglycerides } \\
\text { in humans }\end{array}$ & $\begin{array}{l}\text { NATURE } \\
\text { GENETICS }\end{array}$ & 715 \\
\hline 97 & 2011 & $\begin{array}{l}\text { Baigent, C; Landray, MJ; Reith, C; } \\
\text { Emberson, J; Wheeler, DC; Tomson, C; } \\
\text { Wanner, C; Krane, V; Cass, A; Craig, J; } \\
\text { Neal, B; Jiang, LX; Hooi, LS; Levin, A; } \\
\text { Agodoa, L; Gaziano, M; Kasiske, B; } \\
\text { Walker, R; Massy, ZA; Feldt-Rasmussen, } \\
\text { B; Krairittichai, U; Ophascharoensuk, V; } \\
\text { Fellstrom, B; Holdaas, H; Tesar, V; } \\
\text { Wiecek, A; Grobbee, D; de Zeeuw, D; } \\
\text { Gronhagen-Riska, C; Dasgupta, T; } \\
\text { Lewis, D; Herrington, W; Mafham, M; } \\
\text { Majoni, W; Wallendszus, K; Grimm, R; } \\
\text { Pedersen, T; Tobert, J; Armitage, J; } \\
\text { Baxter, A; Bray, C; Chen, YP; Chen, ZM; } \\
\text { Hill, M; Knott, C; Parish, S; Simpson, D; } \\
\text { Sleight, P; Young, A; Collins, R }\end{array}$ & $\begin{array}{l}\text { The effects of lowering } \\
\text { LDL cholesterol with } \\
\text { simvastatin plus ezetimibe } \\
\text { in patients with chronic } \\
\text { kidney disease (Study of } \\
\text { Heart and Renal } \\
\text { Protection): A randomised } \\
\text { placebo-controlled trial }\end{array}$ & LANCET & 711 \\
\hline 97 & 2001 & $\begin{array}{l}\text { Chinetti, G; Lestavel, S; Bocher, V; } \\
\text { Remaley, AT; Neve, B; Torra, IP; } \\
\text { Teissier, E; Minnich, A; Jaye, M; } \\
\text { Duverger, N; Brewer, HB; Fruchart, JC; } \\
\text { Clavey, V; Staels, B }\end{array}$ & $\begin{array}{l}\text { PPAR-alpha and } \\
\text { PPAR-gamma activators } \\
\text { induce cholesterol removal } \\
\text { from human macrophage } \\
\text { foam cells through } \\
\text { stimulation of the ABCA1 } \\
\text { pathway }\end{array}$ & $\begin{array}{l}\text { NATURE } \\
\text { MEDICINE }\end{array}$ & 711 \\
\hline 99 & 1960 & Burstein, M; Samaille, J & $\begin{array}{l}\text { Sur un dosage rapide du } \\
\text { cholesterol lie aux } \\
\text { alpha-lipoproteines et aux } \\
\text { beta-lipoproteines du } \\
\text { serum }\end{array}$ & $\begin{array}{l}\text { CLINICA } \\
\text { CHIMICA ACTA }\end{array}$ & 706 \\
\hline 100 & 1969 & Hinckley, CC & $\begin{array}{l}\text { Paramagnetic shifts in } \\
\text { solutions of cholesterol and } \\
\text { dipyridine adduct of } \\
\text { trisdipivalomethanatoeu- } \\
\text { ropium(III). A shift } \\
\text { reagent }\end{array}$ & $\begin{array}{l}\text { JOURNAL OF THE } \\
\text { AMERICAN } \\
\text { CHEMICAL } \\
\text { SOCIETY }\end{array}$ & 700 \\
\hline
\end{tabular}


Table 2

Most-cited papers in cholesterol between January 1, 2006 and December 31, 2015

\begin{tabular}{|c|c|c|c|c|c|}
\hline Rank & Year & Authors & Title & Journal & $\begin{array}{l}\text { Times } \\
\text { cited }\end{array}$ \\
\hline 1 & 2010 & $\begin{array}{l}\text { Baigent, C; Blackwell, L; Emberson, J; } \\
\text { Holland, LE; Reith, C; Bhala, N; Peto, R; } \\
\text { Barnes, EH; Keech, A; Simes, J; } \\
\text { Collins, R }\end{array}$ & $\begin{array}{l}\text { Efficacy and safety of more } \\
\text { intensive lowering of LDL } \\
\text { cholesterol: } \\
\text { A meta-analysis of data } \\
\text { from } 170,000 \text { participants } \\
\text { in } 26 \text { randomised trials }\end{array}$ & LANCET & 1228 \\
\hline 2 & 2011 & $\begin{array}{l}\text { Boden, WE; Probstfield, JL; Anderson, } \\
\text { T; Chaitman, BR; Desvignes-Nickens, P; } \\
\text { Koprowicz, K; McBride, R; Teo, K; } \\
\text { Weintraub, W }\end{array}$ & $\begin{array}{l}\text { Niacin in Patients with } \\
\text { Low HDL Cholesterol } \\
\text { Levels Receiving Intensive } \\
\text { Statin Therapy }\end{array}$ & $\begin{array}{l}\text { NEW ENGLAND } \\
\text { JOURNAL OF } \\
\text { MEDICINE }\end{array}$ & 797 \\
\hline 3 & 2010 & $\begin{array}{l}\text { Duewell, P; Kono, H; Rayner, KJ; Sirois, } \\
\text { CM; Vladimer, G; Bauernfeind, FG; } \\
\text { Abela, GS; Franchi, L; Nunez, G; } \\
\text { Schnurr, M; Espevik, T; Lien, E; } \\
\text { Fitzgerald, KA; Rock, KL; Moore, KJ; } \\
\text { Wright, SD; Hornung, V; Latz, E }\end{array}$ & $\begin{array}{l}\text { NLRP3 inflammasomes are } \\
\text { required for atherogenesis } \\
\text { and activated by cholesterol } \\
\text { crystals }\end{array}$ & NATURE & 790 \\
\hline 4 & 2007 & $\begin{array}{l}\text { Lewington, S; Whitlock, G; Clarke, R; } \\
\text { Sherliker, P; Emberson, J; Halsey, J; } \\
\text { Qizilbash, N; Peto, R; Collins, R }\end{array}$ & $\begin{array}{l}\text { Blood cholesterol and } \\
\text { vascular mortality by age, } \\
\text { sex, and blood pressure: } \\
\text { A meta-analysis of } \\
\text { individual data from } 61 \\
\text { prospective studies with } \\
55,000 \text { vascular deaths }\end{array}$ & LANCET & 776 \\
\hline 5 & 2011 & $\begin{array}{l}\text { Baigent, C; Landray, MJ; Reith, C; } \\
\text { Emberson, J; Wheeler, DC; Tomson, C; } \\
\text { Wanner, C; Krane, V; Cass, A; Craig, J; } \\
\text { Neal, B; Jiang, LX; Hooi, LS; Levin, A; } \\
\text { Agodoa, L; Gaziano, M; Kasiske, B; } \\
\text { Walker, R; Massy, ZA; Feldt-Rasmussen, } \\
\text { B; Krairittichai, U; Ophascharoensuk, V; } \\
\text { Fellstrom, B; Holdaas, H; Tesar, V; } \\
\text { Wiecek, A; Grobbee, D; de Zeeuw, D; } \\
\text { Gronhagen-Riska, C; Dasgupta, T; } \\
\text { Lewis, D; Herrington, W; Mafham, M; } \\
\text { Majoni, W; Wallendszus, K; Grimm, R; } \\
\text { Pedersen, T; Tobert, J; Armitage, J; } \\
\text { Baxter, A; Bray, C; Chen, YP; Chen, ZM; } \\
\text { Hill, M; Knott, C; Parish, S; Simpson, D; } \\
\text { Sleight, P; Young, A; Collins, R }\end{array}$ & $\begin{array}{l}\text { The effects of lowering } \\
\text { LDL cholesterol with } \\
\text { simvastatin plus ezetimibe } \\
\text { in patients with chronic } \\
\text { kidney disease (Study of } \\
\text { Heart and Renal } \\
\text { Protection): A randomised } \\
\text { placebo-controlled trial }\end{array}$ & LANCET & 739 \\
\hline 6 & 2008 & $\begin{array}{l}\text { Kathiresan, S; Melander, O; Guiducci, C; } \\
\text { Surti, A; Burtt, NP; Rieder, MJ; Cooper, } \\
\text { GM; Roos, C; Voight, BF; Havulinna, } \\
\text { AS; Wahlstrand, B; Hedner, T; Corella, } \\
\text { D; Tai, ES; Ordovas, JM; Berglund, G; } \\
\text { Vartiainen, E; Jousilahti, P; Hedblad, B; } \\
\text { Taskinen, MR; Newton-Cheh, C; } \\
\text { Salomaa, V; Peltonen, L; Groop, L; } \\
\text { Altshuler, DM; Orho-Melander, M }\end{array}$ & $\begin{array}{l}\text { Six new loci associated } \\
\text { with blood low-density } \\
\text { lipoprotein cholesterol, } \\
\text { high-density lipoprotein } \\
\text { cholesterol or triglycerides } \\
\text { in humans }\end{array}$ & $\begin{array}{l}\text { NATURE } \\
\text { GENETICS }\end{array}$ & 731 \\
\hline 7 & 2007 & $\begin{array}{l}\text { Barter, P; Gotto, AM; LaRosa, JC; } \\
\text { Maroni, J; Szarek, M; Grundy, SM; } \\
\text { Kastelein, JJP; Bittner, V; Fruchart, JC }\end{array}$ & $\begin{array}{l}\text { HDL cholesterol, very low } \\
\text { levels of LDL cholesterol, } \\
\text { and cardiovascular events }\end{array}$ & $\begin{array}{l}\text { NEW ENGLAND } \\
\text { JOURNAL OF } \\
\text { MEDICINE }\end{array}$ & 710 \\
\hline
\end{tabular}


Table 2

(Continued)

\begin{tabular}{|c|c|c|c|c|c|}
\hline Rank & Year & Authors & Title & Journal & $\begin{array}{c}\text { Times } \\
\text { cited }\end{array}$ \\
\hline 8 & 2008 & $\begin{array}{l}\text { Kearney, PM; Blackwell, L; Collins, R; } \\
\text { Keech, A; Simes, J; Peto, R; Armitage, J; } \\
\text { Baigent, C }\end{array}$ & $\begin{array}{l}\text { Efficacy of } \\
\text { cholesterol-lowering } \\
\text { therapy in } 18,686 \text { people } \\
\text { with diabetes in } 14 \\
\text { randomised trials of statins: } \\
\text { A meta-analysis }\end{array}$ & LANCET & 647 \\
\hline 9 & 2011 & $\begin{array}{l}\text { Khera, AV; Cuchel, M; de la Llera-Moya, } \\
\text { M; Rodrigues, A; Burke, MF; Jafri, K; } \\
\text { French, BC; Phillips, JA; Mucksavage, } \\
\text { ML; Wilensky, RL; Mohler, ER; } \\
\text { Rothblat, GH; Rader, DJ }\end{array}$ & $\begin{array}{l}\text { Cholesterol Efflux } \\
\text { Capacity, High-Density } \\
\text { Lipoprotein Function, and } \\
\text { Atherosclerosis }\end{array}$ & $\begin{array}{l}\text { NEW ENGLAND } \\
\text { JOURNAL OF } \\
\text { MEDICINE }\end{array}$ & 625 \\
\hline 10 & 2012 & $\begin{array}{l}\text { Voight, BF; Peloso, GM; Orho-Melander, } \\
\text { M; Frikke-Schmidt, R; Barbalic, M; } \\
\text { Jensen, MK; Hindy, G; Holm, H; Ding, } \\
\text { EL; Johnson, T; Schunkert, H; Samani, } \\
\text { NJ; Clarke, R; Hopewell, JC; Thompson, } \\
\text { JF; Li, MY; Thorleifsson, G; } \\
\text { Newton-Cheh, C; Musunuru, K; } \\
\text { Pirruccello, JP; Saleheen, D; Chen, L; } \\
\text { Stewart, AFR; Schillert, A; } \\
\text { Thorsteinsdottir, U; Thorgeirsson, G; } \\
\text { Anand, S; Engert, JC; Morgan, T; } \\
\text { Spertus, J; Stoll, M; Berger, K; } \\
\text { Martinelli, N; Girelli, D; McKeown, PP; } \\
\text { Patterson, CC; Epstein, SE; Devaney, J; } \\
\text { Burnett, MS; Mooser, V; Ripatti, S; } \\
\text { Surakka, I; Nieminen, MS; Sinisalo, J; } \\
\text { Lokki, ML; Perola, M; Havulinna, A; de } \\
\text { Faire, U; Gigante, B; Ingelsson, E; Zeller, } \\
\text { T; Wild, P; de Bakker, PIW; Klungel, } \\
\text { OH; Maitland-van der Zee, AH; Peters, } \\
\text { BJM; de Boer, A; Grobbee, DE; } \\
\text { Kamphuisen, PW; Deneer, VHM; Elbers, } \\
\text { CC; Onland-Moret, NC; Hofker, MH; } \\
\text { Wijmenga, C; Verschuren, WMM; Boer, } \\
\text { JMA; van der Schouw, YT; Rasheed, A; } \\
\text { Frossard, P; Demissie, S; Willer, C; Do, } \\
\text { R; Ordovas, JM; Abecasis, GR; Boehnke, } \\
\text { M; Mohlke, KL; Daly, MJ; Guiducci, C; } \\
\text { Burtt, NP; Surti, A; Gonzalez, E; Purcell, } \\
\text { S; Gabriel, S; Marrugat, J; Peden, J; } \\
\text { Erdmann, J; Diemert, P; Willenborg, C; } \\
\text { Konig, IR; Fischer, M; Hengstenberg, C; } \\
\text { Ziegler, A; Buysschaert, I; Lambrechts, } \\
\text { D; Van de Werf, F; Fox, KA; } \\
\text { El Mokhtari, NE; Rubin, D; } \\
\text { Schrezenmeir, J; Schreiber, S; Schafer, } \\
\text { A; Danesh, J; Blankenberg, S; Roberts, } \\
\text { R; McPherson, R; Watkins, H; Hall, AS; } \\
\text { Overvad, K; Rimm, E; Boerwinkle, E; } \\
\text { Tybjaerg-Hansen, A; Cupples, LA; } \\
\text { Reilly, MP; Melander, O; Mannucci, PM; }\end{array}$ & $\begin{array}{l}\text { Plasma HDL cholesterol } \\
\text { and risk of myocardial } \\
\text { infarction: A mendelian } \\
\text { randomisation study }\end{array}$ & LANCET & 535 \\
\hline
\end{tabular}


Table 2

(Continued)

\begin{tabular}{|c|c|c|c|c|c|}
\hline Rank & Year & Authors & Title & Journal & $\begin{array}{l}\text { Times } \\
\text { cited }\end{array}$ \\
\hline & & $\begin{array}{l}\text { Ardissino, D; Siscovick, D; Elosua, R; } \\
\text { Stefansson, K; O’Donnell, CJ; Salomaa, } \\
\text { V; Rader, DJ; Peltonen, L; Schwartz, } \\
\text { SM; Altshuler, D; Kathiresan, S }\end{array}$ & & & \\
\hline 11 & 2014 & $\begin{array}{l}\text { Stone, NJ; Robinson, JG; Lichtenstein, } \\
\text { AH; Merz, CNB; Blum, CB; Eckel, RH; } \\
\text { Goldberg, AC; Gordon, D; Levy, D; } \\
\text { Lloyd-Jones, DM; McBride, P; Schwartz, } \\
\text { JS; Shero, ST; Smith, SC; Watson, K; } \\
\text { Wilson, PWF }\end{array}$ & $\begin{array}{l}2013 \text { ACC/AHA Guideline } \\
\text { on the Treatment of Blood } \\
\text { Cholesterol to Reduce } \\
\text { Atherosclerotic } \\
\text { Cardiovascular Risk in } \\
\text { Adults A Report of the } \\
\text { American College of } \\
\text { Cardiology/American } \\
\text { Heart Association Task } \\
\text { Force on Practice } \\
\text { Guidelines }\end{array}$ & CIRCULATION & 533 \\
\hline 12 & 2012 & $\begin{array}{l}\text { Mihaylova, B; Emberson, J; Blackwell, } \\
\text { L; Keech, A; Simes, J; Barnes, EH; } \\
\text { Voysey, M; Gray, A; Collins, R; Baigent, } \\
\text { C; de Lemos, J; Braunwald, E; Blazing, } \\
\text { M; Murphy, S; Downs, JR; Gotto, A; } \\
\text { Clearfield, M; Holdaas, H; Gordon, D; } \\
\text { Davis, B; Koren, M; Dahlof, B; Poulter, } \\
\text { N; Sever, P; Knopp, RH; Fellstrom, B; } \\
\text { Holdaas, H; Jardine, A; Schmieder, R; } \\
\text { Zannad, F; Goldbourt, U; Kaplinsky, E; } \\
\text { Colhoun, HM; Betteridge, DJ; } \\
\text { Durrington, PN; Hitman, GA; Fuller, J; } \\
\text { Neil, A; Wanner, C; Krane, V; Sacks, F; } \\
\text { Moye, L; Pfeffer, M; Hawkins, CM; } \\
\text { Braunwald, E; Kjekshus, J; Wedel, H; } \\
\text { Wikstrand, J; Barter, P; Keech, A; } \\
\text { Tavazzi, L; Maggioni, A; Marchioli, R; } \\
\text { Tognoni, G; Franzosi, MG; Maggioni, A; } \\
\text { Bloomfield, H; Robins, S; Collins, R; } \\
\text { Armitage, J; Keech, A; Parish, S; Peto, } \\
\text { R; Sleight, P; Pedersen, TR; Ridker, PM; } \\
\text { Holman, R; Meade, T; Simes, J; Keech, } \\
\text { A; MacMahon, S; Marschner, I; Tonkin, } \\
\text { A; Shaw, J; Serruys, PW; Nakamura, H; } \\
\text { Knatterud, G; Furberg, C; Byington, R; } \\
\text { Macfarlane, P; Cobbe, S; Ford, I; } \\
\text { Murphy, M; Blauw, GJ; Packard, C; } \\
\text { Shepherd, J; Kjekshus, J; Pedersen, T; } \\
\text { Wilhelmsen, L; Braunwald, E; Cannon, } \\
\text { C; Murphy, S; Collins, R; Armitage, J; } \\
\text { Bowman, L; Parish, S; Peto, R; Sleight, } \\
\text { P; Baigent, C; Landray, M; Collins, R; La } \\
\text { Rosa, J; Rossouw, J; Probstfield, J; } \\
\text { Shepherd, J; Cobbe, S; Macfarlane, P; } \\
\text { Ford, I }\end{array}$ & $\begin{array}{l}\text { The effects of lowering } \\
\text { LDL cholesterol with statin } \\
\text { therapy in people at low } \\
\text { risk of vascular disease: } \\
\text { Meta-analysis of individual } \\
\text { data from } 27 \text { randomised } \\
\text { trials }\end{array}$ & LANCET & 496 \\
\hline
\end{tabular}


Table 2

(Continued)

\begin{tabular}{|c|c|c|c|c|c|}
\hline Rank & Year & Authors & Title & Journal & $\begin{array}{l}\text { Times } \\
\text { cited }\end{array}$ \\
\hline 13 & 2014 & $\begin{array}{l}\text { Stone, NJ; Robinson, JG; Lichtenstein, } \\
\text { AH; Merz, CNB; Blum, CB; Eckel, RH; } \\
\text { Goldberg, AC; Gordon, D; Levy, D; } \\
\text { Lloyd-Jones, DM; McBride, P; Schwartz, } \\
\text { JS; Shero, ST; Smith, SC; Watson, K; } \\
\text { Wilson, PWF }\end{array}$ & $\begin{array}{l}2013 \text { ACC/AHA Guideline } \\
\text { on the Treatment of Blood } \\
\text { Cholesterol to Reduce } \\
\text { Atherosclerotic } \\
\text { Cardiovascular Risk in } \\
\text { Adults A Report of the } \\
\text { American College of } \\
\text { Cardiology/American } \\
\text { Heart Association Task } \\
\text { Force on Practice } \\
\text { Guidelines }\end{array}$ & $\begin{array}{l}\text { JOURNAL OF THE } \\
\text { AMERICAN } \\
\text { COLLEGE OF } \\
\text { CARDIOLOGY }\end{array}$ & 475 \\
\hline 14 & 2009 & $\begin{array}{l}\text { Ridker, PM; Danielson, E; Fonseca, } \\
\text { FAH; Genest, J; Gotto, AM; Kastelein, } \\
\text { JJP; Koenig, W; Libby, P; Lorenzatti, AJ; } \\
\text { MacFadyen, JG; Nordestgaard, BG; } \\
\text { Shepherd, J; Willerson, JT; Glynn, RJ }\end{array}$ & $\begin{array}{l}\text { Reduction in C-reactive } \\
\text { protein and LDL } \\
\text { cholesterol and } \\
\text { cardiovascular event rates } \\
\text { after initiation of } \\
\text { rosuvastatin: A prospective } \\
\text { study of the JUPITER trial }\end{array}$ & LANCET & 453 \\
\hline 15 & 2008 & $\begin{array}{l}\text { Hanson, MA; Cherezov, V; Griffith, MT; } \\
\text { Roth, CB; Jaakola, VP; Chien, EYT; } \\
\text { Velasquez, J; Kuhn, P; Stevens, RC }\end{array}$ & $\begin{array}{l}\text { A specific cholesterol } \\
\text { binding site is established } \\
\text { by the } 2.8 \text { angstrom } \\
\text { structure of the human } \\
\text { beta(2)-adrenergic receptor }\end{array}$ & STRUCTURE & 435 \\
\hline 16 & 2010 & $\begin{array}{l}\text { Rayner, KJ; Suarez, Y; Davalos, A; } \\
\text { Parathath, S; Fitzgerald, ML; Tamehiro, } \\
\text { N; Fisher, EA; Moore, KJ; } \\
\text { Fernandez-Hernando, C }\end{array}$ & $\begin{array}{l}\text { MiR-33 Contributes to the } \\
\text { Regulation of Cholesterol } \\
\text { Homeostasis }\end{array}$ & SCIENCE & 414 \\
\hline 17 & 2008 & Ikonen, E & $\begin{array}{l}\text { Cellular cholesterol } \\
\text { trafficking and } \\
\text { compartmentalization }\end{array}$ & $\begin{array}{l}\text { NATURE } \\
\text { REVIEWS } \\
\text { MOLECULAR } \\
\text { CELL BIOLOGY }\end{array}$ & 377 \\
\hline 18 & 2008 & $\begin{array}{l}\text { Kathiresan, S; Melander, O; Anevski, D; } \\
\text { Guiducci, C; Burtt, NP; Roos, C; } \\
\text { Hirschhorn, JN; Berglund, G; Hedblad, } \\
\text { B; Groop, L; Altshuler, DM; } \\
\text { Newton-Cheh, C; Orho-Melander, M }\end{array}$ & $\begin{array}{l}\text { Polymorphisms associated } \\
\text { with cholesterol and risk of } \\
\text { cardiovascular events }\end{array}$ & $\begin{array}{l}\text { NEW ENGLAND } \\
\text { JOURNAL OF } \\
\text { MEDICINE }\end{array}$ & 367 \\
\hline 19 & 2007 & $\begin{array}{l}\text { Nicholls, SJ; Tuzcu, EM; Sipahi, I; } \\
\text { Grasso, AW; Schoenhagen, P; Hu, T; } \\
\text { Wolski, K; Crowe, T; Desai, MY; Hazen, } \\
\text { SL; Kapadia, SR; Nissen, SE }\end{array}$ & $\begin{array}{l}\text { Statins, high-density } \\
\text { lipoprotein cholesterol, and } \\
\text { regression of coronary } \\
\text { atherosclerosis }\end{array}$ & $\begin{array}{l}\text { JAMA-JOURNAL } \\
\text { OF THE } \\
\text { AMERICAN } \\
\text { MEDICAL } \\
\text { ASSOCIATION }\end{array}$ & 363 \\
\hline 20 & 2010 & $\begin{array}{l}\text { Musunuru, K; Strong, A; } \\
\text { Frank-Kamenetsky, M; Lee, NE; Ahfeldt, } \\
\text { T; Sachs, KV; Li, XY; Li, H; } \\
\text { Kuperwasser, N; Ruda, VM; Pirruccello, } \\
\text { JP; Muchmore, B; Prokunina-Olsson, L; } \\
\text { Hall, JL; Schadt, EE; Morales, CR; } \\
\text { Lund-Katz, S; Phillips, MC; Wong, J; } \\
\text { Cantley, W; Racie, T; Ejebe, KG; }\end{array}$ & $\begin{array}{l}\text { From noncoding variant to } \\
\text { phenotype via SORT1 at } \\
\text { the } 1 \text { p13 cholesterol locus }\end{array}$ & NATURE & 361 \\
\hline
\end{tabular}


Table 2

(Continued)

\begin{tabular}{|c|c|c|c|c|c|}
\hline Rank & Year & Authors & Title & Journal & $\begin{array}{l}\text { Times } \\
\text { cited }\end{array}$ \\
\hline & & $\begin{array}{l}\text { Orho-Melander, M; Melander, O; } \\
\text { Koteliansky, V; Fitzgerald, K; Krauss, } \\
\text { RM; Cowan, CA; Kathiresan, S; Rader, } \\
\text { DJ }\end{array}$ & & & \\
\hline 21 & 2007 & Zidovetzki, R; Levitan, I & $\begin{array}{l}\text { Use of cyclodextrins to } \\
\text { manipulate plasma } \\
\text { membrane cholesterol } \\
\text { content: Evidence, } \\
\text { misconceptions and control } \\
\text { strategies }\end{array}$ & $\begin{array}{l}\text { BIOCHIMICA ET } \\
\text { BIOPHYSICA } \\
\text { ACTA- } \\
\text { BIOMEMBRANES }\end{array}$ & 336 \\
\hline 22 & 2010 & $\begin{array}{l}\text { Najafi-Shoushtari, SH; Kristo, F; Li, YX; } \\
\text { Shioda, T; Cohen, DE; Gerszten, RE; } \\
\text { Naar, AM }\end{array}$ & $\begin{array}{l}\text { MicroRNA-33 and the } \\
\text { SREBP Host Genes } \\
\text { Cooperate to Control } \\
\text { Cholesterol Homeostasis }\end{array}$ & SCIENCE & 333 \\
\hline 23 & 2006 & Lee, JK; Grace, KA; Taylor, AJ & $\begin{array}{l}\text { Effect of a pharmacy care } \\
\text { program on medication } \\
\text { adherence and persistence, } \\
\text { blood pressure, and } \\
\text { low-density lipoprotein } \\
\text { cholesterol - A randomized } \\
\text { controlled trial }\end{array}$ & $\begin{array}{l}\text { JAMA-JOURNAL } \\
\text { OF THE } \\
\text { AMERICAN } \\
\text { MEDICAL } \\
\text { ASSOCIATION }\end{array}$ & 328 \\
\hline 24 & 2010 & $\begin{array}{l}\text { Raal, FJ; Santos, RD; Blom, DJ; Marais, } \\
\text { AD; Charng, MJ; Cromwell, WC; } \\
\text { Lachmann, RH; Gaudet, D; Tan, JL; } \\
\text { Chasan-Taber, S; Tribble, DL; Flaim, JD; } \\
\text { Crooke, ST }\end{array}$ & $\begin{array}{l}\text { Mipomersen, an } \\
\text { apolipoprotein B synthesis } \\
\text { inhibitor, for lowering of } \\
\text { LDL cholesterol } \\
\text { concentrations in patients } \\
\text { with homozygous familial } \\
\text { hypercholesterolaemia: } \\
\text { A randomised, } \\
\text { double-blind, } \\
\text { placebo-controlled trial }\end{array}$ & LANCET & 307 \\
\hline 25 & 2011 & $\begin{array}{l}\text { Chapman, MJ; Ginsberg, HN; Amarenco, } \\
\text { P; Andreotti, F; Boren, J; Catapano, AL; } \\
\text { Descamps, OS; Fisher, E; Kovanen, PT; } \\
\text { Kuivenhoven, JA; Lesnik, P; Masana, L; } \\
\text { Nordestgaard, BG; Ray, KK; Reiner, Z; } \\
\text { Taskinen, MR; Tokgozoglu, L; } \\
\text { Tybjaerg-Hansen, A; Watts, GF }\end{array}$ & $\begin{array}{l}\text { Triglyceride-rich } \\
\text { lipoproteins and } \\
\text { high-density lipoprotein } \\
\text { cholesterol in patients at } \\
\text { high risk of cardiovascular } \\
\text { disease: Evidence and } \\
\text { guidance for management }\end{array}$ & $\begin{array}{l}\text { EUROPEAN } \\
\text { HEART JOURNAL }\end{array}$ & 302 \\
\hline 26 & 2008 & $\begin{array}{l}\text { Frank-Kamenetsky, M; Grefhorst, A; } \\
\text { Anderson, NN; Racie, TS; Bramlage, B; } \\
\text { Akinc, A; Butler, D; Charisse, K; Dorkin, } \\
\text { R; Fan, Y; Gamba-Vitalo, C; Hadwiger, } \\
\text { P; Jayaraman, M; John, M; Jayaprakash, } \\
\text { KN; Maier, M; Nechev, L; Rajeev, KG; } \\
\text { Read, T; Rohl, I; Soutschek, J; Tan, P; } \\
\text { Wong, J; Wang, G; Zimmermann, T; de } \\
\text { Fougerolles, A; Vornlocher, HP; Langer, } \\
\text { R; Anderson, DG; Manoharan, M; } \\
\text { Koteliansky, V; Horton, JD; Fitzgerald, K }\end{array}$ & $\begin{array}{l}\text { Therapeutic RNAi } \\
\text { targeting PCSK9 acutely } \\
\text { lowers plasma cholesterol } \\
\text { in rodents and LDL } \\
\text { cholesterol in nonhuman } \\
\text { primates }\end{array}$ & $\begin{array}{l}\text { PROCEEDINGS } \\
\text { OF THE } \\
\text { NATIONAL } \\
\text { ACADEMY OF } \\
\text { SCIENCES OF } \\
\text { THE UNITED } \\
\text { STATES OF } \\
\text { AMERICA }\end{array}$ & 289 \\
\hline
\end{tabular}


Table 2

(Continued)

\begin{tabular}{|c|c|c|c|c|c|}
\hline Rank & Year & Authors & Title & Journal & $\begin{array}{l}\text { Times } \\
\text { cited }\end{array}$ \\
\hline 26 & 2006 & Kalaany, NY; Mangelsdorf, DJ & $\begin{array}{l}\text { LXRs and FXR: The Yin } \\
\text { and Yang of cholesterol } \\
\text { and fat metabolism }\end{array}$ & $\begin{array}{l}\text { ANNUAL REVIEW } \\
\text { OF PHYSIOLOGY }\end{array}$ & 289 \\
\hline 28 & 2008 & Pandey, AK; Sassetti, CM & $\begin{array}{l}\text { Mycobacterial persistance } \\
\text { requires the utilization of } \\
\text { host cholesterol }\end{array}$ & $\begin{array}{l}\text { PROCEEDINGS } \\
\text { OF THE } \\
\text { NATIONAL } \\
\text { ACADEMY OF } \\
\text { SCIENCES OF } \\
\text { THE UNITED } \\
\text { STATES OF } \\
\text { AMERICA }\end{array}$ & 285 \\
\hline 28 & 2007 & $\begin{array}{l}\text { Wang, X; Collins, HL; Ranalletta, M; } \\
\text { Fuki, IV; Billheimer, JT; Rothblat, GH; } \\
\text { Tall, AR; Rader, DJ }\end{array}$ & $\begin{array}{l}\text { Macrophage ABCA1 and } \\
\text { ABCG1, but not SR-BI, } \\
\text { promote macrophage } \\
\text { reverse cholesterol } \\
\text { transport in vivo }\end{array}$ & $\begin{array}{l}\text { JOURNAL OF } \\
\text { CLINICAL } \\
\text { INVESTIGATION }\end{array}$ & 285 \\
\hline 30 & 2006 & $\begin{array}{l}\text { Kotowski, IK; Pertsemlidis, A; Luke, A; } \\
\text { Cooper, RS; Vega, GL; Cohen, JC; } \\
\text { Hobbs, HH }\end{array}$ & $\begin{array}{l}\text { A spectrum of PCSK } 9 \\
\text { Alleles contributes to } \\
\text { plasma levels of } \\
\text { low-density lipoprotein } \\
\text { cholesterol }\end{array}$ & $\begin{array}{l}\text { AMERICAN } \\
\text { JOURNAL OF } \\
\text { HUMAN } \\
\text { GENETICS }\end{array}$ & 274 \\
\hline 31 & 2012 & $\begin{array}{l}\text { Stein, EA; Mellis, S; Yancopoulos, GD; } \\
\text { Stahl, N; Logan, D; Smith, WB; Lisbon, } \\
\text { E; Gutierrez, M; Webb, C; Wu, R; Du, } \\
\text { YL; Kranz, T; Gasparino, E; Swergold, } \\
\text { GD }\end{array}$ & $\begin{array}{l}\text { Effect of a Monoclonal } \\
\text { Antibody to PCSK9 on } \\
\text { LDL Cholesterol }\end{array}$ & $\begin{array}{l}\text { NEW ENGLAND } \\
\text { JOURNAL OF } \\
\text { MEDICINE }\end{array}$ & 267 \\
\hline 32 & 2009 & $\begin{array}{l}\text { Zelcer, N; Hong, C; Boyadjian, R; } \\
\text { Tontonoz, P }\end{array}$ & $\begin{array}{l}\text { LXR Regulates Cholesterol } \\
\text { Uptake Through } \\
\text { Idol-Dependent } \\
\text { Ubiquitination of the LDL } \\
\text { Receptor }\end{array}$ & SCIENCE & 266 \\
\hline 32 & 2007 & $\begin{array}{l}\text { Lorenzo, C; Williams, K; Hunt, KJ; } \\
\text { Haffner, SM }\end{array}$ & $\begin{array}{l}\text { The National Cholesterol } \\
\text { Education Program-Adult } \\
\text { Treatment Panel III, } \\
\text { International Diabetes } \\
\text { Federation, and World } \\
\text { Health Organization } \\
\text { definitions of the metabolic } \\
\text { syndrome as predictors of } \\
\text { incident cardiovascular } \\
\text { disease and diabetes }\end{array}$ & DIABETES CARE & 266 \\
\hline 34 & 2010 & Klaassen, CD; Aleksunes, LM & $\begin{array}{l}\text { Xenobiotic, Bile Acid, and } \\
\text { Cholesterol Transporters: } \\
\text { Function and Regulation }\end{array}$ & $\begin{array}{l}\text { PHARMACOL- } \\
\text { OGICAL } \\
\text { REVIEWS }\end{array}$ & 265 \\
\hline 35 & 2011 & $\begin{array}{l}\text { Carette, JE; Raaben, M; Wong, AC; } \\
\text { Herbert, AS; Obernosterer, G; } \\
\text { Mulherkar, N; Kuehne, AI; Kranzusch, } \\
\text { PJ; Griffin, AM; Ruthel, G; Dal Cin, P; } \\
\text { Dye, JM; Whelan, SP; Chandran, K; } \\
\text { Brummelkamp, TR }\end{array}$ & $\begin{array}{l}\text { Ebola virus entry requires } \\
\text { the cholesterol transporter } \\
\text { Niemann-Pick } \mathrm{C} 1\end{array}$ & NATURE & 259 \\
\hline
\end{tabular}


Table 2

(Continued)

\begin{tabular}{|c|c|c|c|c|c|}
\hline Rank & Year & Authors & Title & Journal & $\begin{array}{l}\text { Times } \\
\text { cited }\end{array}$ \\
\hline 36 & 2006 & Cuchel, M; Rader, DJ & $\begin{array}{l}\text { Macrophage reverse } \\
\text { cholesterol transport - Key } \\
\text { to the regression of } \\
\text { atherosclerosis? }\end{array}$ & CIRCULATION & 249 \\
\hline 37 & 2012 & $\begin{array}{l}\text { Stein, EA; Gipe, D; Bergeron, J; Gaudet, } \\
\text { D; Weiss, R; Dufour, R; Wu, R; Pordy, R }\end{array}$ & $\begin{array}{l}\text { Effect of a monoclonal } \\
\text { antibody to PCSK9, } \\
\text { REGN727/SAR236553, to } \\
\text { reduce low-density } \\
\text { lipoprotein cholesterol in } \\
\text { patients with heterozygous } \\
\text { familial } \\
\text { hypercholesterolaemia on } \\
\text { stable statin dose with or } \\
\text { without ezetimibe therapy: } \\
\text { A phase } 2 \text { randomised } \\
\text { controlled trial }\end{array}$ & LANCET & 243 \\
\hline 38 & 2010 & $\begin{array}{l}\text { Rajamaki, K; Lappalainen, J; Oorni, K; } \\
\text { Valimaki, E; Matikainen, S; Kovanen, } \\
\text { PT; Eklund, KK }\end{array}$ & $\begin{array}{l}\text { Cholesterol Crystals } \\
\text { Activate the NLRP3 } \\
\text { Inflammasome in Human } \\
\text { Macrophages: A Novel } \\
\text { Link between Cholesterol } \\
\text { Metabolism and } \\
\text { Inflammation }\end{array}$ & PLOS ONE & 242 \\
\hline 38 & 2006 & $\begin{array}{l}\text { Shepherd, J; Breazna, A; Barter, P; } \\
\text { LaRosa, J; Carmena, R; Grundy, S; } \\
\text { Deedwania, P; Waters, D; Fruchart, JC; } \\
\text { Haffner, S; Hsia, J }\end{array}$ & $\begin{array}{l}\text { Effect of lowering LDL } \\
\text { cholesterol substantially } \\
\text { below currently } \\
\text { recommended levels in } \\
\text { patients with coronary } \\
\text { heart disease and diabetes - } \\
\text { The treating to new targets } \\
\text { (TNT) study }\end{array}$ & DIABETES CARE & 242 \\
\hline 40 & 2006 & $\begin{array}{l}\text { Barter, PJ; Ballantyne, CM; Carmena, R; } \\
\text { Cabezas, MC; Chapman, MJ; Couture, P; } \\
\text { De Graaf, J; Durrington, PN; Faergeman, } \\
\text { O; Frohlich, J; Furberg, CD; Gagne, C; } \\
\text { Haffner, SM; Humphries, SE; Jungner, I; } \\
\text { Krauss, RM; Kwiterovich, P; Marcovina, } \\
\text { S; Packard, CJ; Pearson, TA; Reddy, KS; } \\
\text { Rosenson, R; Sarrafzadegan, N; } \\
\text { Sniderman, AD; Stalenhoef, AF; Stein, } \\
\text { E; Talmud, PJ; Tonkin, AM; Walldius, G; } \\
\text { Williams, KMS }\end{array}$ & $\begin{array}{l}\text { Apo B versus cholesterol in } \\
\text { estimating cardiovascular } \\
\text { risk and in guiding therapy: } \\
\text { Report of the } \\
\text { thirty-person/ten-country } \\
\text { panel }\end{array}$ & $\begin{array}{l}\text { JOURNAL OF } \\
\text { INTERNAL } \\
\text { MEDICINE }\end{array}$ & 238 \\
\hline 41 & 2012 & $\begin{array}{l}\text { Rosenson, RS; Brewer, HB; Davidson, } \\
\text { WS; Fayad, ZA; Fuster, V; Goldstein, J; } \\
\text { Hellerstein, M; Jiang, XC; Phillips, MC; } \\
\text { Rader, DJ; Remaley, AT; Rothblat, GH; } \\
\text { Tall, AR; Yvan-Charvet, L }\end{array}$ & $\begin{array}{l}\text { Cholesterol Efflux and } \\
\text { Atheroprotection } \\
\text { Advancing the Concept of } \\
\text { Reverse Cholesterol } \\
\text { Transport }\end{array}$ & CIRCULATION & 236 \\
\hline 42 & 2008 & $\begin{array}{l}\text { Tall, AR; Yvan-Charvet, L; Terasaka, N; } \\
\text { Pagler, T; Wang, N }\end{array}$ & $\begin{array}{l}\text { HDL, ABC transporters, } \\
\text { and cholesterol efflux: } \\
\text { Implications for the } \\
\text { treatment of atherosclerosis }\end{array}$ & $\begin{array}{l}\text { CELL } \\
\text { METABOLISM }\end{array}$ & 235 \\
\hline
\end{tabular}


Table 2

(Continued)

\begin{tabular}{|c|c|c|c|c|c|}
\hline Rank & Year & Authors & Title & Journal & $\begin{array}{l}\text { Times } \\
\text { cited }\end{array}$ \\
\hline 43 & 2011 & $\begin{array}{l}\text { Rayner, KJ; Sheedy, FJ; Esau, CC; } \\
\text { Hussain, FN; Temel, RE; Parathath, S; } \\
\text { van Gils, JM; Rayner, AJ; Chang, AN; } \\
\text { Suarez, Y; Fernandez-Hernando, C; } \\
\text { Fisher, EA; Moore, KJ }\end{array}$ & $\begin{array}{l}\text { Antagonism of miR-33 in } \\
\text { mice promotes reverse } \\
\text { cholesterol transport and } \\
\text { regression of } \\
\text { atherosclerosis }\end{array}$ & $\begin{array}{l}\text { JOURNAL OF } \\
\text { CLINICAL } \\
\text { INVESTIGATION }\end{array}$ & 230 \\
\hline 44 & 2006 & $\begin{array}{l}\text { Gelissen, IC; Harris, M; Rye, KA; Quinn, } \\
\text { C; Brown, AJ; Kockx, M; Cartland, S; } \\
\text { Packianathan, M; Kritharides, L; Jessup, } \\
\text { W }\end{array}$ & $\begin{array}{l}\text { ABCA1 and ABCG1 } \\
\text { synergize to mediate } \\
\text { cholesterol export to } \\
\text { apoA-I }\end{array}$ & $\begin{array}{l}\text { ARTERIOSCLE- } \\
\text { ROSIS } \\
\text { THROMBOSIS } \\
\text { AND VASCULAR } \\
\text { BIOLOGY }\end{array}$ & 227 \\
\hline 44 & 2006 & $\begin{array}{l}\text { Chang, TY; Chang, CCY; Ohgami, N; } \\
\text { Yamauchi, Y }\end{array}$ & $\begin{array}{l}\text { Cholesterol sensing, } \\
\text { trafficking, and } \\
\text { esterification }\end{array}$ & $\begin{array}{l}\text { ANNUAL REVIEW } \\
\text { OF CELL AND DE- } \\
\text { VELOPMENTAL } \\
\text { BIOLOGY }\end{array}$ & 227 \\
\hline 46 & 2008 & Tall, AR & $\begin{array}{l}\text { Cholesterol efflux } \\
\text { pathways and other } \\
\text { potential mechanisms } \\
\text { involved in the } \\
\text { athero-protective effect of } \\
\text { high density lipoproteins }\end{array}$ & $\begin{array}{l}\text { JOURNAL OF } \\
\text { INTERNAL } \\
\text { MEDICINE }\end{array}$ & 221 \\
\hline 46 & 2006 & $\begin{array}{l}\text { Mari, M; Caballero, F; Colell, A; } \\
\text { Morales, A; Caballeria, J; Fernandez, A; } \\
\text { Enrich, C; Fernandez-Checa, JC; } \\
\text { Garcia-Ruiz, C }\end{array}$ & $\begin{array}{l}\text { Mitochondrial free } \\
\text { cholesterol loading } \\
\text { sensitizes to TNF- and } \\
\text { Fas-mediated } \\
\text { steatohepatitis }\end{array}$ & $\begin{array}{l}\text { CELL } \\
\text { METABOLISM }\end{array}$ & 221 \\
\hline 48 & 2006 & $\begin{array}{l}\text { Naik, SU; Wang, X; Da Silva, JS; Jaye, } \\
\text { M; Macphee, CH; Reilly, MP; } \\
\text { Billheimer, JT; Rothblat, GH; Rader, DJ }\end{array}$ & $\begin{array}{l}\text { Pharmacological activation } \\
\text { of liver X receptors } \\
\text { promotes reverse } \\
\text { cholesterol transport in } \\
\text { vivo }\end{array}$ & CIRCULATION & 220 \\
\hline 49 & 2009 & $\begin{array}{l}\text { Briel, M; Ferreira-Gonzalez, I; You, JJ; } \\
\text { Karanicolas, PJ; Akl, EA; Wu, P; } \\
\text { Blechacz, B; Bassler, D; Wei, XG; } \\
\text { Sharman, A; Whitt, I; da Silva, SA; } \\
\text { Khalid, Z; Nordmann, AJ; Zhou, Q; } \\
\text { Walter, SD; Vale, N; Bhatnagar, N; } \\
\text { O'Regan, C; Mills, EJ; Bucher, HC; } \\
\text { Montori, VM; Guyatt, GH }\end{array}$ & $\begin{array}{l}\text { Association between } \\
\text { change in high density } \\
\text { lipoprotein cholesterol and } \\
\text { cardiovascular disease } \\
\text { morbidity and mortality: } \\
\text { Systematic review and } \\
\text { meta-regression analysis }\end{array}$ & $\begin{array}{l}\text { BRITISH } \\
\text { MEDICAL } \\
\text { JOURNAL }\end{array}$ & 218 \\
\hline 50 & 2007 & $\begin{array}{l}\text { Akuta, N; Suzuki, F; Kawamura, Y; } \\
\text { Yatsuji, H; Sezaki, H; Suzuki, Y; Hosaka, } \\
\text { T; Kobayashi, M; Kobayashi, M; Arase, } \\
\text { Y; Ikeda, K; Kumada, H }\end{array}$ & $\begin{array}{l}\text { Predictive factors of early } \\
\text { and sustained responses to } \\
\text { peginterferon plus ribavirin } \\
\text { combination therapy in } \\
\text { Japanese patients infected } \\
\text { with hepatitis C virus } \\
\text { genotype } 1 \text { b: Amino acid } \\
\text { substitutions in the core } \\
\text { region and low-density } \\
\text { lipoprotein cholesterol } \\
\text { levels }\end{array}$ & $\begin{array}{l}\text { JOURNAL OF } \\
\text { HEPATOLOGY }\end{array}$ & 217 \\
\hline
\end{tabular}


Table 2

(Continued)

\begin{tabular}{|c|c|c|c|c|c|}
\hline Rank & Year & Authors & Title & Journal & $\begin{array}{l}\text { Times } \\
\text { cited }\end{array}$ \\
\hline 50 & 2007 & $\begin{array}{l}\text { Van der Geize, R; Yam, K; Heuser, T; } \\
\text { Wilbrink, MH; Hara, H; Anderton, MC; } \\
\text { Sim, E; Dijkhuizen, L; Davies, JE; } \\
\text { Mohn, WW; Eltis, LD }\end{array}$ & $\begin{array}{l}\text { A gene cluster encoding } \\
\text { cholesterol catabolism in a } \\
\text { soil actinomycete provides } \\
\text { insight into Mycobacterium } \\
\text { tuberculosis survival in } \\
\text { macrophages }\end{array}$ & $\begin{array}{l}\text { PROCEEDINGS } \\
\text { OF THE } \\
\text { NATIONAL } \\
\text { ACADEMY OF } \\
\text { SCIENCES OF } \\
\text { THE UNITED } \\
\text { STATES OF } \\
\text { AMERICA }\end{array}$ & 217 \\
\hline 52 & 2006 & Oram, JF; Vaughan, AM & $\begin{array}{l}\text { ATP-binding cassette } \\
\text { cholesterol transporters and } \\
\text { cardiovascular disease }\end{array}$ & $\begin{array}{l}\text { CIRCULATION } \\
\text { RESEARCH }\end{array}$ & 215 \\
\hline 53 & 2008 & $\begin{array}{l}\text { Frikke-Schmidt, R; Nordestgaard, BG; } \\
\text { Stene, MCA; Sethi, AA; Remaley, AT; } \\
\text { Schnohr, P; Grande, P; } \\
\text { Tybjaerg-Hansen, A }\end{array}$ & $\begin{array}{l}\text { Association of } \\
\text { loss-of-function mutations } \\
\text { in the ABCA1 gene with } \\
\text { high-density lipoprotein } \\
\text { cholesterol levels and risk } \\
\text { of ischemic heart disease }\end{array}$ & $\begin{array}{l}\text { JAMA-JOURNAL } \\
\text { OF THE } \\
\text { AMERICAN } \\
\text { MEDICAL } \\
\text { ASSOCIATION }\end{array}$ & 214 \\
\hline 54 & 2008 & $\begin{array}{l}\text { Sandhu, MS; Waterworth, DM; } \\
\text { Debenham, SL; Wheeler, E; Papadakis, } \\
\text { K; Zhao, JH; Song, KJ; Yuan, X; } \\
\text { Johnson, T; Ashford, S; Inouye, M; } \\
\text { Luben, R; Sims, M; Hadley, D; McArdle, } \\
\text { W; Barter, P; Kesaniemi, YA; Mahley, } \\
\text { RW; McPherson, R; Grundy, SM; } \\
\text { Bingham, SA; Khaw, KT; Loos, RJF; } \\
\text { Waeber, G; Barroso, I; Strachan, DP; } \\
\text { Deloukas, P; Vollenweider, P; Wareham, } \\
\text { NJ; Mooser, V }\end{array}$ & $\begin{array}{l}\text { LDL-cholesterol } \\
\text { concentrations: } \\
\text { A genome-wide association } \\
\text { study }\end{array}$ & LANCET & 210 \\
\hline 54 & 2006 & $\begin{array}{l}\text { Deedwania, P; Barter, P; Carmena, R; } \\
\text { Fruchart, JC; Grundy, SM; Haffner, S; } \\
\text { Kastelein, JJP; LaRosa, JC; Schachner, } \\
\text { H; Shepherd, J; Waters, DD }\end{array}$ & $\begin{array}{l}\text { Reduction of low-density } \\
\text { lipoprotein cholesterol in } \\
\text { patients with coronary } \\
\text { heart disease and metabolic } \\
\text { syndrome: Analysis of the } \\
\text { Treating to New Targets } \\
\text { study }\end{array}$ & LANCET & 210 \\
\hline 56 & 2011 & $\begin{array}{l}\text { Griffin, JE; Gawronski, JD; DeJesus, } \\
\text { MA; Ioerger, TR; Akerley, BJ; Sassetti, } \\
\text { CM }\end{array}$ & $\begin{array}{l}\text { High-Resolution } \\
\text { Phenotypic Profiling } \\
\text { Defines Genes Essential for } \\
\text { Mycobacterial Growth and } \\
\text { Cholesterol Catabolism }\end{array}$ & $\begin{array}{l}\text { PLOS } \\
\text { PATHOGENS }\end{array}$ & 208 \\
\hline 56 & 2007 & $\begin{array}{l}\text { Mehta, JL; Sanada, N; Hu, CP; Chen, } \\
\text { JW; Dandapat, A; Sugawara, F; Satoh, H; } \\
\text { Inoue, K; Kawase, Y; Jishage, K; Suzuki, } \\
\text { H; Takeya, M; Schnackenberg, L; Beger, } \\
\text { R; Hermonat, PL; Thomas, M; } \\
\text { Sawamura, T }\end{array}$ & $\begin{array}{l}\text { Deletion of LOX-1 reduces } \\
\text { atherogenesis in LDLR } \\
\text { knockout mice fed high } \\
\text { cholesterol diet }\end{array}$ & $\begin{array}{l}\text { CIRCULATION } \\
\text { RESEARCH }\end{array}$ & 208 \\
\hline 58 & 2012 & $\begin{array}{l}\text { Raal, F; Scott, R; Somaratne, R; Bridges, } \\
\text { I; Li, G; Wasserman, SM; Stein, EA }\end{array}$ & $\begin{array}{l}\text { Low-Density Lipoprotein } \\
\text { Cholesterol-Lowering } \\
\text { Effects of AMG 145, } \\
\text { a Monoclonal Antibody to }\end{array}$ & CIRCULATION & 206 \\
\hline
\end{tabular}


Table 2

(Continued)

\begin{tabular}{|c|c|c|c|c|c|}
\hline Rank & Year & Authors & Title & Journal & $\begin{array}{l}\text { Times } \\
\text { cited }\end{array}$ \\
\hline & & & $\begin{array}{l}\text { Proprotein Convertase } \\
\text { Subtilisin/Kexin Type } 9 \\
\text { Serine Protease in Patients } \\
\text { with Heterozygous Familial } \\
\text { Hypercholesterolemia: the } \\
\text { Reduction of LDL-C with } \\
\text { PCSK9 Inhibition in } \\
\text { Heterozygous Familial } \\
\text { Hypercholesterolemia } \\
\text { Disorder (RUTHERFORD) } \\
\text { Randomized Trial }\end{array}$ & & \\
\hline 59 & 2011 & $\begin{array}{l}\text { Nicholls, SJ; Brewer, HB; Kastelein, JJP; } \\
\text { Krueger, KA; Wang, MD; Shao, MY; Hu, } \\
\text { B; McErlean, E; Nissen, SE }\end{array}$ & $\begin{array}{l}\text { Effects of the CETP } \\
\text { Inhibitor Evacetrapib } \\
\text { Administered as } \\
\text { Monotherapy or in } \\
\text { Combination with Statins } \\
\text { on HDL and LDL } \\
\text { Cholesterol A Randomized } \\
\text { Controlled Trial }\end{array}$ & $\begin{array}{l}\text { JAMA-JOURNAL } \\
\text { OF THE } \\
\text { AMERICAN } \\
\text { MEDICAL } \\
\text { ASSOCIATION }\end{array}$ & 204 \\
\hline 60 & 2008 & $\begin{array}{l}\text { Miller, M; Cannon, CP; Murphy, SA; } \\
\text { Qin, J; Ray, KK; Braunwald, E }\end{array}$ & $\begin{array}{l}\text { Impact of triglyceride } \\
\text { levels beyond low-density } \\
\text { lipoprotein cholesterol after } \\
\text { acute coronary syndrome in } \\
\text { the PROVE IT-TIMI } 22 \\
\text { trial }\end{array}$ & $\begin{array}{l}\text { JOURNAL OF THE } \\
\text { AMERICAN } \\
\text { COLLEGE OF } \\
\text { CARDIOLOGY }\end{array}$ & 203 \\
\hline 61 & 2012 & $\begin{array}{l}\text { Sainz, B; Barretto, N; Martin, DN; } \\
\text { Hiraga, N; Imamura, M; Hussain, S; } \\
\text { Marsh, KA; Yu, XM; Chayama, K; } \\
\text { Alrefai, WA; Uprichard, SL }\end{array}$ & $\begin{array}{l}\text { Identification of the } \\
\text { Niemann-Pick C1-like } 1 \\
\text { cholesterol absorption } \\
\text { receptor as a new hepatitis } \\
\text { C virus entry factor }\end{array}$ & $\begin{array}{l}\text { NATURE } \\
\text { MEDICINE }\end{array}$ & 201 \\
\hline 62 & 2010 & $\begin{array}{l}\text { Armitage, J; Bowman, L; Wallendszus, } \\
\text { K; Bulbulia, R; Rahimi, K; Haynes, R; } \\
\text { Parish, S; Peto, R; Collins, R; Meade, T; } \\
\text { Sleight, P; Collins, R; Armitage, J; } \\
\text { Bowman, L; Parish, S; Peto, R; Barton, J; } \\
\text { Bray, C; Wincott, E; Dayanandan, R; } \\
\text { Clarke, R; Graham, I; Simpson, D; } \\
\text { Warlow, C; Wilken, D; Tobert, J; } \\
\text { Mushner, T; Doll, R; Wilhelmsen, L; } \\
\text { Fox, K; Hill, C; Sandercock, P; Webster, } \\
\text { J; Henderson, J; Nixon, A; Lackie, S; } \\
\text { Thompson, J; Brown, M; Blackwood, S; } \\
\text { Morgan, M; Rhoden, W; Saeed, B; } \\
\text { Houghton, M; Nicholson, A; Simpson, } \\
\text { C; Hoburn, B; Cooper, I; Gallivan, A; } \\
\text { Pickerell, E; Hancock, J; Watkinson, J; } \\
\text { Ryder, B; Jones, S; Burbridge, W; } \\
\text { Kitchen, M; Leary, HO; Verow, C; } \\
\text { Meynell, L; Rollinson, L; Bain, S; Jones, } \\
\text { A; Jewkes, C; Russon, C; Bateson, M; } \\
\text { Gill, P; Nicol, J; Bayly, G; }\end{array}$ & $\begin{array}{l}\text { Intensive lowering of LDL } \\
\text { cholesterol with } 80 \mathrm{mg} \\
\text { versus } 20 \mathrm{mg} \text { simvastatin } \\
\text { daily in } 12,064 \text { survivors of } \\
\text { myocardial infarction: } \\
\text { A double-blind randomised } \\
\text { trial }\end{array}$ & LANCET & 199 \\
\hline
\end{tabular}


Table 2

(Continued)

\begin{tabular}{|c|c|c|c|c|}
\hline Rank & Year & Authors & Journal & $\begin{array}{l}\text { Times } \\
\text { cited }\end{array}$ \\
\hline & & $\begin{array}{l}\text { Stansbie, D; Andrews, G; Halestrap, M; } \\
\text { Meredith, J; Best, R; Appleyard, D; } \\
\text { Briggs, R; Wareing, H; Holmes, K; Holt, } \\
\text { J; Kenyon, M; White, C; Khalifa, M; } \\
\text { Newton, D; Wass, A; Watkinson, R; } \\
\text { Creamer, J; Anderson, S; Bethell, A; } \\
\text { Butler, C; Castro, K; Washington, M; } \\
\text { Weston, M; Cleaver, K; Machin, J; Wray, } \\
\text { R; Sinclair, J; Van Aalst, A; Been, M; } \\
\text { Mattu, R; Bates, D; Burke, A; Gill, L; } \\
\text { Walton, E; Cowley, M; Robson, H; } \\
\text { Graham, A; Rose, G; Kerr, M; Mallinson, } \\
\text { J; Peascod, B; Donnelly, R; Kalk, J; } \\
\text { Scott, A; Gibson, T; Hannah, J; Henshaw, } \\
\text { L; Margetts, M; Pearson, N; Frost, S; } \\
\text { Murray, S; Marshall, A; Went, J; Inman, } \\
\text { A; Simmonds, J; Teasdale, A; Kemp, T; } \\
\text { Roberts, G; Kooner, J; Cahill, S; Lloyd, } \\
\text { M; Molloy, O; Wigley, J; Galvin, M; } \\
\text { Wilder, C; Lindley, R; Shaw, S; } \\
\text { Swainson, C; Hillis, L; Johnston, J; } \\
\text { Johnstone, A; Miller, D; Kennedy, M; } \\
\text { Mushahwar, S; Savage, M; Appleyard, } \\
\text { D; Ayer, G; Schofield, J; Greenhalgh, S; } \\
\text { Parks, J; Speak, S; Coulson, C; } \\
\text { Papouchado, M; Carpenter, R; Wisby, J; } \\
\text { Cobbe, S; Campbell, C; Hunter, J; } \\
\text { Young, H; Gallacher, M; Lindsay, D; } \\
\text { Halliday, A; Godfrey, S; Donahoo, LO; } \\
\text { Chambers, J; Wierzbicki, A; Jones, A; } \\
\text { Parkin, D; Nwafor, K; Oldroyd, K; } \\
\text { Vallance, B; Cunningham, N; Moreland, } \\
\text { G; Oldroyd, C; Young, H; Crawford, M; } \\
\text { Hillson, R; Knott, K; Mahabir, N; } \\
\text { Crouch, A; MacDonald, Y; Bellamy, C; } \\
\text { Green, J; Brown, L; Heron, J; Jones, N; } \\
\text { Roberts, M; Hainsworth, D; Williams, J; } \\
\text { Barnes, P; Fitchet, A; Longworth, C; } \\
\text { Davidson, J; Irvine, N; Oliver, R; Pond, } \\
\text { C; Nuttall, M; Mostyn, RL; Brown, M; } \\
\text { Barrowcliffe, J; Blackburn, S; Furnell, } \\
\text { W; Webster, S; Wheatley, L; Hudson, I; } \\
\text { Pohl, J; Nicholson, S; Mallya, S; Nash, } \\
\text { M; Spruce, J; Bonner, A; Leather, J; } \\
\text { Searle, A; Davies, E; Egdell, R; Price, B; } \\
\text { Bennett, AT; Horton, S; Cunnington, A; } \\
\text { Giles, P; Sidaway, J; Tomlinson, L; } \\
\text { Walton, E; Hawkins, L; Long, J; Murphy, } \\
\text { J; Brennan, G; Boon, M; Cassidy, S; } \\
\text { Rodger, C; Hunter, J; McNeilly, A; } \\
\text { Moreland, G; Radcliffe, A; Farrer, M; } \\
\text { Bluett, J; Cowell, L; Farrell, A; Gilroy, S; }\end{array}$ & & \\
\hline
\end{tabular}


Table 2

(Continued)

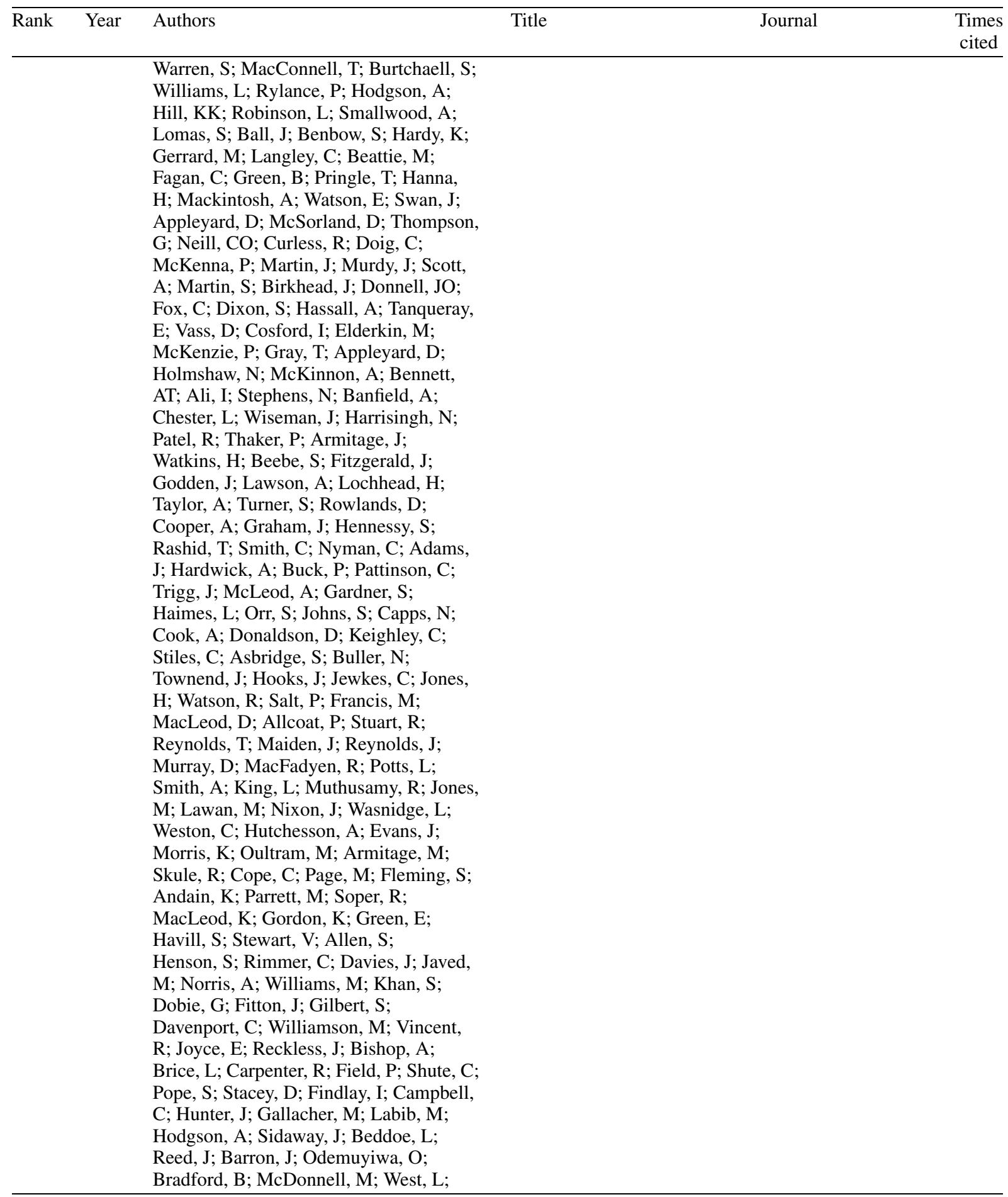


Table 2

(Continued)

\begin{tabular}{|c|c|c|c|c|}
\hline Rank & Year & Authors & Journal & $\begin{array}{c}\text { Times } \\
\text { cited }\end{array}$ \\
\hline & & $\begin{array}{l}\text { Beck, P; Gilbey, S; Clarkson, A; Drury, } \\
\text { K; Hall, S; Quartey, D; Whittam, B; } \\
\text { Lund, D; Stott, L; Griffiths, H; } \\
\text { Appleyard, D; Fitzgerald, J; Kudarenko, } \\
\text { A; Watkins, J; Golledge, S; Pottle, J; } \\
\text { Little, S; Paine, B; Shears, C; Baxter, M; } \\
\text { Wilkinson, P; Chambers, R; Hamper, C; } \\
\text { Hollister, E; Ramsay, H; Barber, J; } \\
\text { Hopkins, T; Hughes, L; Whittaker, JE; } \\
\text { Verow, C; Burke, RL; Lloyd, C; Dhawan, } \\
\text { J; John, J; Bramley, D; Catchpole, A; } \\
\text { Colecchia, A; Gray, C; LeQuelenec, M; } \\
\text { Remington, D; Wiseman, J; Gray, C; } \\
\text { Anderson, P; Woolass, R; Thomas, P; } \\
\text { Weston, C; Guy, F; Lynch, J; Thomas, R; } \\
\text { Coates, S; Gait, M; Waller, D; Elkins, K; } \\
\text { Franklin, M; Moore, L; Signy, M; } \\
\text { Chilton, R; Joyce, E; Wrapson, C; } \\
\text { Wiltshire, C; Lewis, P; Curtis, J; Toole, } \\
\text { JO; Scanlon, S; Carey, C; Dobson, L; } \\
\text { Gould, M; Mansfield, H; Ranson, G; } \\
\text { Rodaway, M; Germon, J; Cockcroft, J; } \\
\text { McDowell, I; Field, R; Whiting, J; } \\
\text { Dennison, C; Roberts, D; Cooper, M; } \\
\text { Davies, C; Fitton, J; Hutt, L; Radford, L; } \\
\text { Ward, L; Williamson, M; McAlpine, H; } \\
\text { Dougall, H; Robertson, L; Scott, L; } \\
\text { Young, H; Humphrey, P; Saminaden, S; } \\
\text { Watling, D; Davies, J; Owen, L; } \\
\text { Clements, M; Walker, E; Atkins, E; } \\
\text { Lindley, R; Shaw, T; Swainson, C; Webb, } \\
\text { D; MacCallum, H; Markie, D; Melville, } \\
\text { V; Adamson, L; Johnston, A; Polukord, } \\
\text { E; Rudden, M; Hogan, J; Lie, F; Badger, } \\
\text { V; Duffy, S; Mitchell, C; MacQueen, E; } \\
\text { Baxter, R; Campbell, S; McDonald, L; } \\
\text { Wood, H; Munro, A; Pycock, C; } \\
\text { Cadwell, J; Doughty, A; Harvey, M; } \\
\text { Price, S; Aldersley, M; Lock, S; Pendrey, } \\
\text { P; Barton, J; Bray, C; Dayanandan, R; } \\
\text { Wmcott, E; Achiri, P; Anderson, C; } \\
\text { Benham, J; Bojowsky, H; Boller, I; } \\
\text { Booker, V; Brewer, A; Brindley, G; } \\
\text { Cobb, L; Collett, A; Corbett, M; } \\
\text { Crowther, J; Pour, SD; Edmunds, K; } \\
\text { Fortun, A; Grimsey, T; Harwood, C; } \\
\text { Hope, C; Jones, R; Jones, S; Kidney, K; } \\
\text { King, M; Knight, S; Lang, H; Madgwick, } \\
\text { Z; Marsden, C; Matthews, C; } \\
\text { Matthewson, M; Miller, J; Moss, B; } \\
\text { Mostefai, Y; Murphy, K; Naughten, A; } \\
\text { Pickworth, S; Radley, A; Southren, S; } \\
\text { Sutherland, S; Tong, R; Turakani, M; }\end{array}$ & & \\
\hline
\end{tabular}


Table 2

(Continued)

\begin{tabular}{|c|c|c|c|c|c|}
\hline Rank & Year & Authors & Title & Journal & $\begin{array}{l}\text { Times } \\
\text { cited }\end{array}$ \\
\hline & & $\begin{array}{l}\text { Umbrath, M; Armitage, J; Baigent, C; } \\
\text { Bowman, L; Bulbulia, R; Chen, Z; } \\
\text { Clarke, R; Collins, R; Dunachie, S; } \\
\text { Dasgupta, T; Haynes, R; Landray, M; } \\
\text { Mafham, M; Majoni, W; Murray, C; } \\
\text { Naessens, K; Porter, T; Rahimi, K; Reith, } \\
\text { C; Clarke, MT; Turnbull, C; Walter, K; } \\
\text { Harding, P; Lay, M; Wallendszus, K; } \\
\text { Berry, C; Bettesworth, H; Booth, J; } \\
\text { Bowes, M; Bu, Y; Charles, A; Cody, A; } \\
\text { Cox, J; Emberson, J; Goodwin, N; Hurt, } \\
\text { C; Link, E; McCabe, P; Munday, A; } \\
\text { Murawska, A; Offer, A; Palmer, A; } \\
\text { Parish, S; Peto, R; Prajapati, N; Tochlin, } \\
\text { S; Young, A; Young, A; Clark, S; } \\
\text { Kourelhas, K; Radley, M; Ambrose, V; } \\
\text { Bradley, M; Bush, E; Chavagnon, T; } \\
\text { Chukwurah, B; Crowley, S; Dunseath, J; } \\
\text { Emmens, K; Fletcher, L; Gordon, J; } \\
\text { Gordon, A; Hickman, C; Hill, J; Ji, M; } \\
\text { Lee, A; Luker, N; Norris, S; Priestley, H; } \\
\text { Sullivan, J; Taylor, J; Wintour, J; Yeung, } \\
\text { M; Youngman, L; Beebe, S; Fitzgerald, J; } \\
\text { Godden, J; Haimes, L; Lawson, A; } \\
\text { Lochhead, H; McDonnell, M; Nash, M; } \\
\text { Taylor, A; Bennett, AT; Walton, E }\end{array}$ & & & \\
\hline 63 & 2008 & $\begin{array}{l}\text { Wouters, K; van Gorp, PJ; Bieghs, V; } \\
\text { Gijbels, MJ; Duimel, H; Lutjohann, D; } \\
\text { Kerksiek, A; van Kruchten, R; Maeda, N; } \\
\text { Staels, B; van Bilsen, M; Shiri-Sverdlov, } \\
\text { R; Hofker, MH }\end{array}$ & $\begin{array}{l}\text { Dietary cholesterol, rather } \\
\text { than liver steatosis, leads to } \\
\text { hepatic inflammation in } \\
\text { hyperlipidemic mouse } \\
\text { models of nonalcoholic } \\
\text { steatohepatitis }\end{array}$ & HEPATOLOGY & 199 \\
\hline 63 & 2007 & $\begin{array}{l}\text { Bogers, RP; Bemelmans, WJE; } \\
\text { Hoogenveen, RT; Boshuizen, HC; } \\
\text { Woodward, M; Knekt, P; van Dam, RM; } \\
\text { Hu, FB; Visscher, TLS; Menotti, A; } \\
\text { Thorpe, RJ; Jamrozik, K; Calling, S; } \\
\text { Strand, BH; Shipley, MJ }\end{array}$ & $\begin{array}{l}\text { Association of overweight } \\
\text { with increased risk of } \\
\text { coronary heart disease } \\
\text { partly independent of blood } \\
\text { pressure and cholesterol } \\
\text { levels - A meta-analysis of } \\
21 \text { cohort studies including } \\
\text { more than } 300,000 \text { persons }\end{array}$ & $\begin{array}{l}\text { ARCHIVES OF } \\
\text { INTERNAL } \\
\text { MEDICINE }\end{array}$ & 199 \\
\hline 65 & 2009 & $\begin{array}{l}\text { Kwon, HJ; Abi-Mosleh, L; Wang, ML; } \\
\text { Deisenhofer, J; Goldstein, JL; Brown, } \\
\text { MS; Infante, RE }\end{array}$ & $\begin{array}{l}\text { Structure of N-Terminal } \\
\text { Domain of NPC1 Reveals } \\
\text { Distinct Subdomains for } \\
\text { Binding and Transfer of } \\
\text { Cholesterol }\end{array}$ & CELL & 197 \\
\hline 66 & 2009 & $\begin{array}{l}\text { Demonty, I; Ras, RT; van der Kniap, } \\
\text { HCM; Duchateau, GSMJF; Meijer, L; } \\
\text { Zock, PL; Geleijnse, JM; Trautwein, EA }\end{array}$ & $\begin{array}{l}\text { Continuous Dose-Response } \\
\text { Relationship of the } \\
\text { LDL-Cholesterol-Lowering } \\
\text { Effect of Phytosterol Intake }\end{array}$ & $\begin{array}{l}\text { JOURNAL OF } \\
\text { NUTRITION }\end{array}$ & 194 \\
\hline
\end{tabular}


Table 2

(Continued)

\begin{tabular}{|c|c|c|c|c|c|}
\hline Rank & Year & Authors & Title & Journal & $\begin{array}{l}\text { Times } \\
\text { cited }\end{array}$ \\
\hline 66 & 2006 & $\begin{array}{l}\text { Kastelein, JJP; Wedel, MK; Baker, BF; } \\
\text { Su, J; Bradley, JD; Yu, RZ; Chuang, E; } \\
\text { Graham, MJ; Crooke, RM }\end{array}$ & $\begin{array}{l}\text { Potent reduction of } \\
\text { apolipoprotein B and } \\
\text { low-density lipoprotein } \\
\text { cholesterol by short-term } \\
\text { administration of an } \\
\text { antisense inhibitor of } \\
\text { apolipoprotein B }\end{array}$ & CIRCULATION & 194 \\
\hline 66 & 2006 & $\begin{array}{l}\text { Portincasa, P; Moschetta, A; Palasciano, } \\
\text { G }\end{array}$ & $\begin{array}{l}\text { Cholesterol gallstone } \\
\text { disease }\end{array}$ & LANCET & 194 \\
\hline 69 & 2007 & $\begin{array}{l}\text { Zhang, YY; Guo, KY; LeBlanc, RE; Loh, } \\
\text { D; Schwartz, GJ; Yu, YH }\end{array}$ & $\begin{array}{l}\text { Increasing dietary leucine } \\
\text { intake reduces diet-induced } \\
\text { obesity and improves } \\
\text { glucose and cholesterol } \\
\text { metabolism in mice via } \\
\text { multimechanisms }\end{array}$ & DIABETES & 185 \\
\hline 69 & 2006 & $\begin{array}{l}\text { Li, YC; Park, MJ; Ye, SK; Kim, CW; } \\
\text { Kim, YN }\end{array}$ & $\begin{array}{l}\text { Elevated levels of } \\
\text { cholesterol-rich lipid rafts } \\
\text { in cancer cells are } \\
\text { correlated with apoptosis } \\
\text { sensitivity induced by } \\
\text { cholesterol-depleting } \\
\text { agents }\end{array}$ & $\begin{array}{l}\text { AMERICAN } \\
\text { JOURNAL OF } \\
\text { PATHOLOGY }\end{array}$ & 185 \\
\hline 71 & 2009 & $\begin{array}{l}\text { Rader, DJ; Alexander, ET; Weibel, GL; } \\
\text { Billheimer, J; Rothblat, GH }\end{array}$ & $\begin{array}{l}\text { The role of reverse } \\
\text { cholesterol transport in } \\
\text { animals and humans and } \\
\text { relationship to } \\
\text { atherosclerosis }\end{array}$ & $\begin{array}{l}\text { JOURNAL OF } \\
\text { LIPID RESEARCH }\end{array}$ & 183 \\
\hline 72 & 2007 & $\begin{array}{l}\text { Liu, Q; Zerbinatti, CV; Zhang, J; Hoe, } \\
\text { HS; Wang, B; Cole, SL; Herz, J; Muglia, } \\
\text { L; Bu, GJ }\end{array}$ & $\begin{array}{l}\text { Amyloid precursor protein } \\
\text { regulates brain } \\
\text { apolipoprotein e and } \\
\text { cholesterol metabolism } \\
\text { through lipoprotein } \\
\text { receptor LRP1 }\end{array}$ & NEURON & 182 \\
\hline 73 & 2006 & $\begin{array}{l}\text { Matsuura, F; Wang, N; Chen, WG; Jiang, } \\
\text { XC; Tall, AR }\end{array}$ & $\begin{array}{l}\text { HDL from CETP-deficient } \\
\text { subjects shows enhanced } \\
\text { ability to promote } \\
\text { cholesterol efflux from } \\
\text { macrophages in an apoE- } \\
\text { and ABCG1-dependent } \\
\text { pathway }\end{array}$ & $\begin{array}{l}\text { JOURNAL OF } \\
\text { CLINICAL } \\
\text { INVESTIGATION }\end{array}$ & 180 \\
\hline 74 & 2009 & Brown, MS; Goldstein, JL & $\begin{array}{l}\text { Cholesterol feedback: } \\
\text { From Schoenheimer's } \\
\text { bottle to Scap's MELADL }\end{array}$ & $\begin{array}{l}\text { JOURNAL OF } \\
\text { LIPID RESEARCH }\end{array}$ & 179 \\
\hline 74 & 2007 & $\begin{array}{l}\text { Temel, RE; Tang, WQ; Ma, YY; Rudel, } \\
\text { LL; Willingham, MC; Ioannou, YA; } \\
\text { Davies, JP; Nilsson, LM; Yu, LQ }\end{array}$ & $\begin{array}{l}\text { Hepatic Niemann-Pick } \\
\text { C1-like } 1 \text { regulates biliary } \\
\text { cholesterol concentration } \\
\text { and is a target of ezetirnibe }\end{array}$ & $\begin{array}{l}\text { JOURNAL OF } \\
\text { CLINICAL } \\
\text { INVESTIGATION }\end{array}$ & 179 \\
\hline
\end{tabular}


Table 2

(Continued)

\begin{tabular}{|c|c|c|c|c|c|}
\hline Rank & Year & Authors & Title & Journal & $\begin{array}{l}\text { Times } \\
\text { cited }\end{array}$ \\
\hline 76 & 2012 & $\begin{array}{l}\text { Boekholdt, SM; Arsenault, BJ; Mora, S; } \\
\text { Pedersen, TR; LaRosa, JC; Nestel, PJ; } \\
\text { Simes, RJ; Durrington, P; Hitman, GA; } \\
\text { Welch, KMA; DeMicco, DA; } \\
\text { Zwinderman, AH; Clearfield, MB; } \\
\text { Downs, JR; Tonkin, AM; Colhoun, HM; } \\
\text { Gotto, AM; Ridker, PM; Kastelein, JJP }\end{array}$ & $\begin{array}{l}\text { Association of LDL } \\
\text { Cholesterol, Non-HDL } \\
\text { Cholesterol, and } \\
\text { Apolipoprotein B Levels } \\
\text { with Risk of } \\
\text { Cardiovascular Events } \\
\text { Among Patients Treated } \\
\text { with Statins A } \\
\text { Meta-analysis }\end{array}$ & $\begin{array}{l}\text { JAMA-JOURNAL } \\
\text { OF THE } \\
\text { AMERICAN } \\
\text { MEDICAL } \\
\text { ASSOCIATION }\end{array}$ & 178 \\
\hline 76 & 2011 & Di Paolo, G; Kim, TW & $\begin{array}{l}\text { Linking lipids to } \\
\text { Alzheimer's disease: } \\
\text { Cholesterol and beyond }\end{array}$ & $\begin{array}{l}\text { NATURE } \\
\text { REVIEWS } \\
\text { NEUROSCIENCE }\end{array}$ & 178 \\
\hline 78 & 2010 & Yvan-Charvet, L; Wang, N; Tall, AR & $\begin{array}{l}\text { Role of HDL, ABCA1, and } \\
\text { ABCG1 Transporters in } \\
\text { Cholesterol Efflux and } \\
\text { Immune Responses }\end{array}$ & $\begin{array}{l}\text { ARTERIOSCLE- } \\
\text { ROSIS } \\
\text { THROMBOSIS } \\
\text { AND VASCULAR } \\
\text { BIOLOGY }\end{array}$ & 177 \\
\hline 78 & 2009 & $\begin{array}{l}\text { Rog, T; Pasenkiewicz-Gierula, M; } \\
\text { Vattulainen, I; Karttunen, M }\end{array}$ & $\begin{array}{l}\text { Ordering effects of } \\
\text { cholesterol and its } \\
\text { analogues }\end{array}$ & $\begin{array}{l}\text { BIOCHIMICA ET } \\
\text { BIOPHYSICA } \\
\text { ACTA- } \\
\text { BIOMEMBRANES }\end{array}$ & 177 \\
\hline 80 & 2008 & $\begin{array}{l}\text { van der Steeg, WA; Holme, I; Boekholdt, } \\
\text { SM; Larsen, ML; Lindahl, C; Stroes, } \\
\text { ESG; Tikkanen, MJ; Wareham, NJ; } \\
\text { Faergeman, O; Olsson, AG; Pedersen, } \\
\text { TR; Khaw, KT; Kastelein, JJP }\end{array}$ & $\begin{array}{l}\text { High-density lipoprotein } \\
\text { cholesterol, high-density } \\
\text { lipoprotein particle size, } \\
\text { and apolipoprotein A-I: } \\
\text { Significance for } \\
\text { cardiovascular risk - The } \\
\text { IDEAL and EPIC-Norfolk } \\
\text { studies }\end{array}$ & $\begin{array}{l}\text { JOURNAL OF THE } \\
\text { AMERICAN } \\
\text { COLLEGE OF } \\
\text { CARDIOLOGY }\end{array}$ & 174 \\
\hline 81 & 2009 & $\begin{array}{l}\text { Chan, JCY; Piper, DE; Cao, QO; Liu, } \\
\text { DM; King, C; Wang, W; Tang, J; Liu, Q; } \\
\text { Higbee, J; Xia, Z; Di, YM; Shetterly, S; } \\
\text { Arimura, Z; Salomonis, H; Romanow, } \\
\text { WG; Thibault, ST; Zhang, R; Cao, P; } \\
\text { Yang, XP; Yu, T; Lu, M; Retter, MW; } \\
\text { Kwon, G; Henne, K; Pan, O; Tsai, MM; } \\
\text { Fuchslocher, B; Yang, E; Zhou, L; Lee, } \\
\text { KJ; Daris, M; Sheng, J; Wang, Y; Shen, } \\
\text { WD; Yeh, WC; Emery, M; Walker, NPC; } \\
\text { Shan, B; Schwarz, M; Jackson, SM }\end{array}$ & $\begin{array}{l}\text { A proprotein convertase } \\
\text { subtilisin/kexin type } 9 \\
\text { neutralizing antibody } \\
\text { reduces serum cholesterol } \\
\text { in mice and nonhuman } \\
\text { primates }\end{array}$ & $\begin{array}{l}\text { PROCEEDINGS } \\
\text { OF THE } \\
\text { NATIONAL } \\
\text { ACADEMY OF } \\
\text { SCIENCES OF } \\
\text { THE UNITED } \\
\text { STATES OF } \\
\text { AMERICA }\end{array}$ & 171 \\
\hline 82 & 2011 & $\begin{array}{l}\text { Farzadfar, F; Finucane, MM; Danaei, G; } \\
\text { Pelizzari, PM; Cowan, MJ; Paciorek, CJ; } \\
\text { Singh, GM; Lin, JK; Stevens, GA; Riley, } \\
\text { LM; Ezzati, M }\end{array}$ & $\begin{array}{l}\text { National, regional, and } \\
\text { global trends in serum total } \\
\text { cholesterol since } 1980 \text { : } \\
\text { Systematic analysis of } \\
\text { health examination surveys } \\
\text { and epidemiological } \\
\text { studies with } 321 \\
\text { country-years and } 3.0 \\
\text { million participants }\end{array}$ & LANCET & 170 \\
\hline 83 & 2012 & $\begin{array}{l}\text { Sullivan, D; Olsson, AG; Scott, R; Kim, } \\
\text { JB; Xue, A; Gebski, V; Wasserman, SM; }\end{array}$ & $\begin{array}{l}\text { Effect of a Monoclonal } \\
\text { Antibody to PCSK9 on }\end{array}$ & $\begin{array}{l}\text { JAMA-JOURNAL } \\
\text { OF THE }\end{array}$ & 168 \\
\hline
\end{tabular}


Table 2

(Continued)

\begin{tabular}{|c|c|c|c|c|c|}
\hline Rank & Year & Authors & Title & Journal & $\begin{array}{l}\text { Times } \\
\text { cited }\end{array}$ \\
\hline & & Stein, EA & $\begin{array}{l}\text { Low-Density Lipoprotein } \\
\text { Cholesterol Levels in } \\
\text { Statin-Intolerant Patients } \\
\text { The GAUSS Randomized } \\
\text { Trial }\end{array}$ & $\begin{array}{l}\text { AMERICAN } \\
\text { MEDICAL } \\
\text { ASSOCIATION }\end{array}$ & \\
\hline 84 & 2006 & $\begin{array}{l}\text { Oksman, M; Livonen, H; Hogyes, E; } \\
\text { Amtul, Z; Penke, B; Leenders, I; } \\
\text { Broersen, L; Lutjohann, D; Hartmann, T; } \\
\text { Tanila, H }\end{array}$ & $\begin{array}{l}\text { Impact of different } \\
\text { saturated fatty acid, } \\
\text { polyunsaturated fatty acid } \\
\text { and cholesterol containing } \\
\text { diets on beta-amyloid } \\
\text { accumulation in APP/PS1 } \\
\text { transgenic mice }\end{array}$ & $\begin{array}{l}\text { NEUROBIOLOGY } \\
\text { OF DISEASE }\end{array}$ & 165 \\
\hline 85 & 2007 & $\begin{array}{l}\text { Kapadia, SB; Barth, H; Baumert, T; } \\
\text { McKeating, JA; Chisari, FV }\end{array}$ & $\begin{array}{l}\text { Initiation of hepatitis C } \\
\text { virus infection is dependent } \\
\text { on cholesterol and } \\
\text { cooperativity between } \\
\text { CD81 and scavenger } \\
\text { receptor B type I }\end{array}$ & $\begin{array}{l}\text { JOURNAL OF } \\
\text { VIROLOGY }\end{array}$ & 162 \\
\hline 86 & 2007 & $\begin{array}{l}\text { Buch, S; Schafmayer, C; Volzke, H; } \\
\text { Becker, C; Franke, A; von } \\
\text { Eller-Eberstein, H; Kluck, C; Bassmann, } \\
\text { I; Brosch, M; Lammert, F; Miquel, JF; } \\
\text { Nervi, F; Wittig, M; Rosskopf, D; Timm, } \\
\text { B; Holl, C; Seeger, M; ElSharawy, A; Lu, } \\
\text { T; Egberts, J; Fandrich, F; Folsch, UR; } \\
\text { Krawczak, M; Schreiber, S; Nurnberg, P; } \\
\text { Tepel, J; Hampe, J }\end{array}$ & $\begin{array}{l}\text { A genome-wide association } \\
\text { scan identifies the hepatic } \\
\text { cholesterol transporter } \\
\text { ABCG8 as a susceptibility } \\
\text { factor for human gallstone } \\
\text { disease }\end{array}$ & $\begin{array}{l}\text { NATURE } \\
\text { GENETICS }\end{array}$ & 161 \\
\hline 87 & 2008 & $\begin{array}{l}\text { Yvan-Charvet, L; Welch, C; Pagler, TA; } \\
\text { Ranalletta, M; Lamkanfi, M; Han, S; } \\
\text { Ishibashi, M; Li, R; Wang, N; Tall, AR }\end{array}$ & $\begin{array}{l}\text { Increased Inflammatory } \\
\text { Gene Expression in ABC } \\
\text { Transporter-Deficient } \\
\text { Macrophages Free } \\
\text { Cholesterol Accumulation, } \\
\text { Increased Signaling via } \\
\text { Toll-Like Receptors, and } \\
\text { Neutrophil Infiltration of } \\
\text { Atherosclerotic Lesions }\end{array}$ & CIRCULATION & 160 \\
\hline 87 & 2008 & $\begin{array}{l}\text { Infante, RE; Wang, ML; Radhakrishnan, } \\
\text { A; Kwon, HJ; Brown, MS; Goldstein, JL }\end{array}$ & $\begin{array}{l}\text { NPC2 facilitates } \\
\text { bidirectional transfer of } \\
\text { cholesterol between NPC1 } \\
\text { and lipid bilayers, a step in } \\
\text { cholesterol egress from } \\
\text { lysosomes }\end{array}$ & $\begin{array}{l}\text { PROCEEDINGS } \\
\text { OF THE } \\
\text { NATIONAL } \\
\text { ACADEMY OF } \\
\text { SCIENCES OF } \\
\text { THE UNITED } \\
\text { STATES OF } \\
\text { AMERICA }\end{array}$ & 160 \\
\hline 87 & 2008 & Anstey, KJ; Lipnicki, DM; Low, LF & $\begin{array}{l}\text { Cholesterol as a risk factor } \\
\text { for dementia and cognitive } \\
\text { decline: A systematic } \\
\text { review of prospective } \\
\text { studies with meta-analysis }\end{array}$ & $\begin{array}{l}\text { AMERICAN } \\
\text { JOURNAL OF } \\
\text { GERIATRIC } \\
\text { PSYCHIATRY }\end{array}$ & 160 \\
\hline 90 & 2008 & $\begin{array}{l}\text { Zhu, X; Lee, JY; Timmins, JM; Brown, } \\
\text { JM; Boudyguina, E; Mulya, A; }\end{array}$ & $\begin{array}{l}\text { Increased cellular free } \\
\text { cholesterol in }\end{array}$ & $\begin{array}{l}\text { JOURNAL OF } \\
\text { BIOLOGICAL }\end{array}$ & 156 \\
\hline
\end{tabular}


Table 2

(Continued)

\begin{tabular}{|c|c|c|c|c|c|}
\hline Rank & Year & Authors & Title & Journal & $\begin{array}{l}\text { Times } \\
\text { cited }\end{array}$ \\
\hline & & $\begin{array}{l}\text { Gebre, AK; Willingham, MC; Hiltbold, } \\
\text { EM; Mishra, N; Maeda, N; Parks, JS }\end{array}$ & $\begin{array}{l}\text { macrophage-specific } \\
\text { Abca1 knock-out mice } \\
\text { enhances pro-inflammatory } \\
\text { response of macrophages }\end{array}$ & CHEMISTRY & \\
\hline 90 & 2006 & Vaughan, AM; Oram, JF & $\begin{array}{l}\text { ABCA1 and ABCG1 or } \\
\text { ABCG4 act sequentially to } \\
\text { remove cellular cholesterol } \\
\text { and generate } \\
\text { cholesterol-rich HDL }\end{array}$ & $\begin{array}{l}\text { JOURNAL OF } \\
\text { LIPID RESEARCH }\end{array}$ & 156 \\
\hline 90 & 2006 & $\begin{array}{l}\text { Jessup, W; Gelissen, IC; Gaus, K; } \\
\text { Kritharides, L }\end{array}$ & $\begin{array}{l}\text { Roles of ATP binding } \\
\text { cassette transporters A1 } \\
\text { and G1, scavenger receptor } \\
\text { BI and membrane lipid } \\
\text { domains in cholesterol } \\
\text { export from macrophages }\end{array}$ & $\begin{array}{l}\text { CURRENT } \\
\text { OPINION IN } \\
\text { LIPIDOLOGY }\end{array}$ & 156 \\
\hline 93 & 2009 & $\begin{array}{l}\text { Waters, DD; Brotons, C; Chiang, CW; } \\
\text { Ferrieres, J; Foody, J; Jukema, JW; } \\
\text { Santos, RD; Verdejo, J; Messig, M; } \\
\text { McPherson, R; Seung, KB; Tarasenko, L }\end{array}$ & $\begin{array}{l}\text { Lipid Treatment } \\
\text { Assessment Project } 2 \text { A } \\
\text { Multinational Survey to } \\
\text { Evaluate the Proportion of } \\
\text { Patients Achieving } \\
\text { Low-Density Lipoprotein } \\
\text { Cholesterol Goals }\end{array}$ & CIRCULATION & 155 \\
\hline 94 & 2006 & $\begin{array}{l}\text { Martins, IJ; Hone, E; Foster, JK; } \\
\text { Sunram-Lea, SI; Gnjec, A; Fuller, SJ; } \\
\text { Nolan, D; Gandy, SE; Martins, RN }\end{array}$ & $\begin{array}{l}\text { Apolipoprotein E, } \\
\text { cholesterol metabolism, } \\
\text { diabetes, and the } \\
\text { convergence of risk factors } \\
\text { for Alzheimer's disease and } \\
\text { cardiovascular disease }\end{array}$ & $\begin{array}{l}\text { MOLECULAR } \\
\text { PSYCHIATRY }\end{array}$ & 154 \\
\hline 95 & 2006 & $\begin{array}{l}\text { Yang, FJ; Vought, BW; Satterlee, JS; } \\
\text { Walker, AK; Sun, ZYJ; Watts, JL; } \\
\text { DeBeaumont, R; Saito, RM; Hyberts, } \\
\text { SG; Yang, S; Macol, C; Iyer, L; Tjian, R; } \\
\text { van den Heuvel, S; Hart, AC; Wagner, G; } \\
\text { Naar, AM }\end{array}$ & $\begin{array}{l}\text { An ARC/Mediator subunit } \\
\text { required for SREBP control } \\
\text { of cholesterol and lipid } \\
\text { homeostasis }\end{array}$ & NATURE & 152 \\
\hline 96 & 2008 & Degoma, EM; Degoma, RL; Rader, DJ & $\begin{array}{l}\text { Beyond high-density } \\
\text { lipoprotein cholesterol } \\
\text { levels - Evaluating } \\
\text { high-density lipoprotein } \\
\text { function as influenced by } \\
\text { novel therapeutic } \\
\text { approaches }\end{array}$ & $\begin{array}{l}\text { JOURNAL OF THE } \\
\text { AMERICAN } \\
\text { COLLEGE OF } \\
\text { CARDIOLOGY }\end{array}$ & 151 \\
\hline 96 & 2007 & $\begin{array}{l}\text { Bradley, MN; Hong, C; Chen, MY; } \\
\text { Joseph, SB; Wilpitz, DC; Wang, XP; } \\
\text { Lusis, AJ; Collins, A; Hseuh, WA; } \\
\text { Collins, JL; Tangirala, RK; Tontonoz, P }\end{array}$ & $\begin{array}{l}\text { Ligand activation of LXR } \\
\text { beta reverses } \\
\text { atherosclerosis and cellular } \\
\text { cholesterol overload in } \\
\text { mice lacking LXR alpha } \\
\text { and apoE }\end{array}$ & $\begin{array}{l}\text { JOURNAL OF } \\
\text { CLINICAL } \\
\text { INVESTIGATION }\end{array}$ & 151 \\
\hline 96 & 2006 & $\begin{array}{l}\text { Ajayaghosh, A; Vijayakumar, C; } \\
\text { Varghese, R; George, SJ }\end{array}$ & $\begin{array}{l}\text { Cholesterol-aided } \\
\text { supramolecular control } \\
\text { over chromophore packing: } \\
\text { Twisted and coiled helices }\end{array}$ & $\begin{array}{l}\text { ANGEWANDTE } \\
\text { CHEMIE- } \\
\text { INTERNATIONAL } \\
\text { EDITION }\end{array}$ & 151 \\
\hline
\end{tabular}


Table 2

(Continued)

\begin{tabular}{|c|c|c|c|c|c|}
\hline Rank & Year & Authors & Title & Journal & $\begin{array}{l}\text { Times } \\
\text { cited }\end{array}$ \\
\hline & & & $\begin{array}{l}\text { with distinct optical, } \\
\text { chiroptical, and } \\
\text { morphological features }\end{array}$ & & \\
\hline 99 & 2008 & $\begin{array}{l}\text { Erlund, I; Koli, R; Alfthan, G; Marniemi, } \\
\text { J; Puukka, P; Mustonen, P; Mattila, P; } \\
\text { Jula, A }\end{array}$ & $\begin{array}{l}\text { Favorable effects of berry } \\
\text { consumption on platelet } \\
\text { function, blood pressure, } \\
\text { and HDL cholesterol }\end{array}$ & $\begin{array}{l}\text { AMERICAN } \\
\text { JOURNAL OF } \\
\text { CLINICAL } \\
\text { NUTRITION }\end{array}$ & 150 \\
\hline 99 & 2007 & $\begin{array}{l}\text { Kodama, S; Tanaka, S; Saito, K; Shu, M; } \\
\text { Sone, Y; Onitake, F; Suzuki, E; Shimano, } \\
\text { H; Yamamoto, S; Kondo, K; Ohashi, Y; } \\
\text { Yamada, N; Sone, H }\end{array}$ & $\begin{array}{l}\text { Effect of aerobic exercise } \\
\text { training on serum levels of } \\
\text { high-density lipoprotein } \\
\text { cholesterol - } \\
\text { A meta-analysis }\end{array}$ & $\begin{array}{l}\text { ARCHIVES OF } \\
\text { INTERNAL } \\
\text { MEDICINE }\end{array}$ & 150 \\
\hline
\end{tabular}

Table 3

Journal/study-type cross tabulation 1916-2015

\begin{tabular}{|c|c|c|c|c|c|c|}
\hline Journal & $\begin{array}{c}\text { Cholesterol and } \\
\text { disease }\end{array}$ & $\begin{array}{l}\text { Cholesterol meta- } \\
\text { bolism/homeo- } \\
\text { stasis }\end{array}$ & $\begin{array}{c}\text { Cholesterol } \\
\text { lowering drugs }\end{array}$ & $\begin{array}{l}\text { Methods for } \\
\text { measuring } \\
\text { cholesterol }\end{array}$ & $\begin{array}{l}\text { Cholesterol } \\
\text { biochem- } \\
\text { istry/biophysics }\end{array}$ & $\begin{array}{c}\text { Total } \\
\text { articles }\end{array}$ \\
\hline $\begin{array}{l}\text { NEW ENGLAND JOURNAL } \\
\text { OF MEDICINE }\end{array}$ & 9 & 3 & 7 & & & 19 \\
\hline LANCET & 7 & & 7 & & & 14 \\
\hline SCIENCE & 1 & 11 & & & & 12 \\
\hline $\begin{array}{l}\text { JAMA-JOURNAL OF THE } \\
\text { AMERICAN MEDICAL } \\
\text { ASSOCIATION }\end{array}$ & 6 & & 3 & 2 & & 11 \\
\hline $\begin{array}{l}\text { PROCEEDINGS OF THE } \\
\text { NATIONAL ACADEMY OF } \\
\text { SCIENCES OF THE UNITED } \\
\text { STATES OF AMERICA }\end{array}$ & 1 & 5 & & & & 6 \\
\hline CIRCULATION & 4 & & 2 & & & 6 \\
\hline CLINICAL CHEMISTRY & & & & 6 & & 6 \\
\hline $\begin{array}{l}\text { BRITISH MEDICAL } \\
\text { JOURNAL }\end{array}$ & 2 & & 3 & & & 5 \\
\hline $\begin{array}{l}\text { JOURNAL OF LIPID } \\
\text { RESEARCH }\end{array}$ & & 1 & & 3 & 1 & 5 \\
\hline $\begin{array}{l}\text { BIOCHIMICA ET } \\
\text { BIOPHYSICA ACTA }\end{array}$ & & 2 & & & 2 & 4 \\
\hline $\begin{array}{l}\text { JOURNAL OF BIOLOGICAL } \\
\text { CHEMISTRY }\end{array}$ & & & & 3 & 1 & 4 \\
\hline $\begin{array}{l}\text { AMERICAN JOURNAL OF } \\
\text { CLINICAL NUTRITION }\end{array}$ & & 3 & & & & 3 \\
\hline $\begin{array}{l}\text { ANNUAL REVIEW OF } \\
\text { BIOCHEMISTRY }\end{array}$ & 1 & 1 & & & & 2 \\
\hline NATURE MEDICINE & & 1 & 1 & & & 2 \\
\hline NATURE & 1 & 1 & & & & 2 \\
\hline DIABETES CARE & 1 & & 1 & & & 2 \\
\hline
\end{tabular}


Table 3

(Continued)

\begin{tabular}{|c|c|c|c|c|c|c|}
\hline Journal & $\begin{array}{c}\text { Cholesterol and } \\
\text { disease }\end{array}$ & $\begin{array}{l}\text { Cholesterol meta- } \\
\text { bolism/homeo- } \\
\text { stasis }\end{array}$ & $\begin{array}{l}\text { Cholesterol } \\
\text { lowering drugs }\end{array}$ & $\begin{array}{l}\text { Methods for } \\
\text { measuring } \\
\text { cholesterol }\end{array}$ & $\begin{array}{l}\text { Cholesterol } \\
\text { biochem- } \\
\text { istry/biophysics }\end{array}$ & $\begin{array}{c}\text { Total } \\
\text { articles }\end{array}$ \\
\hline$\overline{\text { CELL }}$ & & 2 & & & & 2 \\
\hline $\begin{array}{l}\text { ANNALS OF INTERNAL } \\
\text { MEDICINE }\end{array}$ & 2 & & & & & 2 \\
\hline MOLECULAR CELL & 1 & 1 & & & & 2 \\
\hline $\begin{array}{l}\text { JOURNAL OF CLINICAL } \\
\text { INVESTIGATION }\end{array}$ & 1 & 1 & & & & 2 \\
\hline $\begin{array}{l}\text { ARCHIVES OF INTERNAL } \\
\text { MEDICINE }\end{array}$ & & & 1 & & & 1 \\
\hline METABOLISM & & 1 & & & & 1 \\
\hline CLINICA CHIMICA ACTA & & & & 1 & & 1 \\
\hline NATURE GENETICS & & 1 & & & & 1 \\
\hline $\begin{array}{l}\text { JOURNAL OF LABORATORY } \\
\text { AND CLINICAL MEDICINE }\end{array}$ & & & & 1 & & 1 \\
\hline ANALYTICAL CHEMISTRY & & & & 1 & & 1 \\
\hline BIOCHEMISTRY & & & & & 1 & 1 \\
\hline $\begin{array}{l}\text { PROCEEDINGS OF THE } \\
\text { NATIONAL ACADEMY OF } \\
\text { SCIENCES OF THE UNITED } \\
\text { STATES OF } \\
\text { AMERICA-BIOLOGICAL } \\
\text { SCIENCES }\end{array}$ & & & 1 & & & 1 \\
\hline $\begin{array}{l}\text { JOURNAL OF ORGANIC } \\
\text { CHEMISTRY }\end{array}$ & & & & & 1 & 1 \\
\hline $\begin{array}{l}\text { ZEITSCHRIFT FUR } \\
\text { KLINISCHE CHEMIE UND } \\
\text { KLINISCHE BIOCHEMIE }\end{array}$ & & & & 1 & & 1 \\
\hline $\begin{array}{l}\text { JOURNAL OF THE } \\
\text { AMERICAN CHEMICAL } \\
\text { SOCIETY }\end{array}$ & & & & & 1 & 1 \\
\hline $\begin{array}{l}\text { AMERICAN JOURNAL OF } \\
\text { CLINICAL PATHOLOGY }\end{array}$ & & & & 1 & & 1 \\
\hline
\end{tabular}

This table shows the frequency distribution of the 100 most-cited papers of the last century by both research category (enumerated in the column headers) and journal (identified in the table rows). Each article was assigned one or two research categories. 
Table 4

Journal/study-type cross tabulation 2006-2015

\begin{tabular}{|c|c|c|c|c|c|}
\hline Journal & $\begin{array}{l}\text { Cholesterol meta- } \\
\text { bolism/homeo- } \\
\text { stasis }\end{array}$ & $\begin{array}{l}\text { Cholesterol } \\
\text { and disease }\end{array}$ & $\begin{array}{l}\text { Cholesterol } \\
\text { lowering } \\
\text { drugs }\end{array}$ & $\begin{array}{l}\text { Cholesterol } \\
\text { biochem- } \\
\text { istry/biophysics }\end{array}$ & $\begin{array}{c}\text { Total } \\
\text { articles }\end{array}$ \\
\hline$\overline{\text { LANCET }}$ & 2 & 10 & 9 & & 21 \\
\hline CIRCULATION & 4 & 6 & 3 & & 13 \\
\hline $\begin{array}{l}\text { JAMA-JOURNAL OF THE } \\
\text { AMERICAN MEDICAL } \\
\text { ASSOCIATION }\end{array}$ & 1 & 3 & 5 & & 9 \\
\hline $\begin{array}{l}\text { JOURNAL OF THE } \\
\text { AMERICAN COLLEGE OF } \\
\text { CARDIOLOGY }\end{array}$ & 3 & 2 & 3 & & 8 \\
\hline $\begin{array}{l}\text { NEW ENGLAND JOURNAL } \\
\text { OF MEDICINE }\end{array}$ & 3 & 2 & 2 & & 7 \\
\hline $\begin{array}{l}\text { JOURNAL OF CLINICAL } \\
\text { INVESTIGATION }\end{array}$ & 4 & 1 & 1 & & 6 \\
\hline $\begin{array}{l}\text { PROCEEDINGS OF THE } \\
\text { NATIONAL ACADEMY OF } \\
\text { SCIENCES OF THE UNITED } \\
\text { STATES OF AMERICA }\end{array}$ & 3 & & 2 & & 5 \\
\hline CIRCULATION RESEARCH & 2 & 2 & & & 4 \\
\hline NATURE & 3 & 1 & & & 4 \\
\hline CELL METABOLISM & 2 & 2 & & & 4 \\
\hline $\begin{array}{l}\text { JOURNAL OF LIPID } \\
\text { RESEARCH }\end{array}$ & 3 & 1 & & & 4 \\
\hline NATURE GENETICS & 2 & 1 & & & 3 \\
\hline $\begin{array}{l}\text { JOURNAL OF INTERNAL } \\
\text { MEDICINE }\end{array}$ & 1 & 2 & & & 3 \\
\hline DIABETES CARE & & 2 & 1 & & 3 \\
\hline SCIENCE & 3 & & & & 3 \\
\hline MOLECULAR PSYCHIATRY & 1 & & 1 & & 2 \\
\hline $\begin{array}{l}\text { ARTERIOSCLEROSIS } \\
\text { THROMBOSIS AND } \\
\text { VASCULAR BIOLOGY }\end{array}$ & 2 & & & & 2 \\
\hline $\begin{array}{l}\text { BIOCHIMICA ET } \\
\text { BIOPHYSICA } \\
\text { ACTA-BIOMEMBRANES }\end{array}$ & & & 1 & 1 & 2 \\
\hline $\begin{array}{l}\text { ARCHIVES OF INTERNAL } \\
\text { MEDICINE }\end{array}$ & 1 & 1 & & & 2 \\
\hline $\begin{array}{l}\text { EUROPEAN HEART } \\
\text { JOURNAL }\end{array}$ & & 1 & 1 & & 2 \\
\hline JOURNAL OF HEPATOLOGY & 1 & & & 1 & 2 \\
\hline $\begin{array}{l}\text { CURRENT OPINION IN } \\
\text { LIPIDOLOGY }\end{array}$ & 1 & & & & 1 \\
\hline $\begin{array}{l}\text { AMERICAN JOURNAL OF } \\
\text { HUMAN GENETICS }\end{array}$ & 1 & & & & 1 \\
\hline DIABETES & 1 & & & & 1 \\
\hline $\begin{array}{l}\text { AMERICAN JOURNAL OF } \\
\text { CLINICAL NUTRITION }\end{array}$ & 1 & & & & 1 \\
\hline
\end{tabular}


Table 4

(Continued)

\begin{tabular}{|c|c|c|c|c|c|}
\hline Journal & $\begin{array}{l}\text { Cholesterol meta- } \\
\text { bolism/homeo- } \\
\text { stasis }\end{array}$ & $\begin{array}{l}\text { Cholesterol } \\
\text { and disease }\end{array}$ & $\begin{array}{c}\text { Cholesterol } \\
\text { lowering } \\
\text { drugs }\end{array}$ & $\begin{array}{c}\text { Cholesterol } \\
\text { biochem- } \\
\text { istry/biophysics } \\
\end{array}$ & $\begin{array}{l}\text { Total } \\
\text { articles }\end{array}$ \\
\hline PLOS ONE & 1 & & & & 1 \\
\hline NATURE MEDICINE & 1 & & & & 1 \\
\hline $\begin{array}{l}\text { ANGEWANDTE } \\
\text { CHEMIE-INTERNATIONAL } \\
\text { EDITION }\end{array}$ & & & & 1 & 1 \\
\hline $\begin{array}{l}\text { NATURE REVIEWS } \\
\text { MOLECULAR CELL } \\
\text { BIOLOGY }\end{array}$ & 1 & & & & 1 \\
\hline HEPATOLOGY & 1 & & & & 1 \\
\hline $\begin{array}{l}\text { NEUROBIOLOGY OF } \\
\text { DISEASE }\end{array}$ & 1 & & & & 1 \\
\hline $\begin{array}{l}\text { JOURNAL OF BIOLOGICAL } \\
\text { CHEMISTRY }\end{array}$ & 1 & & & & 1 \\
\hline $\begin{array}{l}\text { ANNUAL REVIEW OF CELL } \\
\text { AND DEVELOPMENTAL } \\
\text { BIOLOGY }\end{array}$ & 1 & & & & 1 \\
\hline $\begin{array}{l}\text { NATURE REVIEWS } \\
\text { NEUROSCIENCE }\end{array}$ & & 1 & & & 1 \\
\hline $\begin{array}{l}\text { AMERICAN JOURNAL OF } \\
\text { GERIATRIC PSYCHIATRY }\end{array}$ & & 1 & & & 1 \\
\hline NEURON & 1 & & & & 1 \\
\hline $\begin{array}{l}\text { ANNUAL REVIEW OF } \\
\text { PHYSIOLOGY }\end{array}$ & 1 & & & & 1 \\
\hline $\begin{array}{l}\text { PHARMACOLOGICAL } \\
\text { REVIEWS }\end{array}$ & 1 & & & & 1 \\
\hline $\begin{array}{l}\text { BRITISH MEDICAL } \\
\text { JOURNAL }\end{array}$ & & 1 & & & 1 \\
\hline PLOS PATHOGENS & 1 & & & & 1 \\
\hline STRUCTURE & & & & 1 & 1 \\
\hline JOURNAL OF VIROLOGY & 1 & & & & 1 \\
\hline JOURNAL OF NUTRITION & & & 1 & & 1 \\
\hline CELL & & & & 1 & 1 \\
\hline $\begin{array}{l}\text { AMERICAN JOURNAL OF } \\
\text { PATHOLOGY }\end{array}$ & & & 1 & & 1 \\
\hline
\end{tabular}

\section{Discussion}

It is interesting to see the preponderance of different sub-disciplines in cholesterol research represented in Tables 1 and 2. In particular, the most cited articles over last 10 years shows a shift away from articles describing methods for the measurement of cholesterol towards (increasingly molecular) studies describing cholesterol metabolism/homeostasis, the role of cholesterol in diseases, and cholesterollowering drugs, compared with the most cited articles from the last 100 years. We hypothesize that the complete lack of the cholesterol measurement category in the top-100 list of the last decade, as can be seen in Table 4, indicates that while incremental improvements in this area have continued over the 
last ten years, there has been nothing which one could easily classify as a "quantum leap" producing a highly-cited landmark paper. By contrast, the papers cited in Table 2 suggest that the last 10 years have witnessed the advent of studies describing the role of cholesterol in non-cardiovascular diseases such as cancer (the second reference numbered 69) and Alzheimer's (the second reference numbered 76 and 94). When comparing Tables 3 and 4, another salient feature is the dominance one observes in the most recent period of cardiovascular journals. By comparing the top-10 journals based on number of papers in each of the top-100 articles lists in Tables 3 and 4, one can observe past dominance of journals of a more general nature such as Clinical Chemistry, British Medical Journal, and Science being displaced through the introduction of the Journal of the American College of Cardiology and Circulation Research into the top ten. Also of note is that Circulation rose in the ranking from \#6 to \#2 when considering the most-cited papers of the last decade instead of the last century.

Some of the names in Table 1 will be clearly recognized by the majority of cholesterol research investigators as being "superstars". For example the team of Michael S. Brown and Joseph L. Goldstein, who were awarded the 1985 Nobel prize for Physiology or Medicine 1985 for their work on the regulation of cholesterol metabolism, are jointly authors of nine papers in the most cited articles of the last century (Table 1, numbers 8, 18, 21, 23, 24, 45, 63, 67 and 69) and three from the most cited of the last 10 years (Table 2, numbers 65, 74 and the second reference numbered 87). Other names, especially in Table 2 are "rising stars" who, in the last decade, have made significant contributions to the cholesterol research literature.

\section{Acknowledgements}

The authors would like to thank the referees for their insightful comments.

\section{References}

[1] S. Grundy, Statins: Definitive translational research, Mol Med 20 (2014), 1.

[2] J.S. Kreutzer, A.A. Agyemang, D. Weedon, N. Zasler, M. Oliver, A.A. Sorensen and S. van Wijngaarden, The top 100 cited neurorehabilitation papers, NeuroRehabilitation 40 (2016), 2, Forthcoming. 